\title{
Automatic analysis of the Gorkha earthquake aftershock sequence: evidences of structurally segmented seismicity
}

\author{
Christian Baillard, ${ }^{1,2}$ Hélène Lyon-Caen, ${ }^{1}$ Laurent Bollinger, ${ }^{2}$ Andreas Rietbrock, ${ }^{3}$ \\ Jean Letort ${ }^{4}$ and Lok Bijaya Adhikari ${ }^{5}$ \\ ${ }^{1}$ Laboratoire de Géologie, Ecole Normale Supérieure/CNRS UMR 8538, PSL Research University, Paris F-75005, France. \\ E-mail: baillard@uw.edu \\ ${ }^{2}$ CEA, DAM, DIF, F-91297 Arpajon, France \\ ${ }^{3}$ Department of Earth, Ocean and Ecological Sciences, University of Liverpool, Liverpool L69 3GP, United Kingdom \\ ${ }^{4}$ ISTerre, F-38000 Grenoble, France \\ ${ }^{5}$ Department of Mines and Geology, National Seismological Center, Kathmandu 44600, Nepal
}

Accepted 2017 February 23. Received 2017 February 21; in original form 2016 December 5

\begin{abstract}
SUMMAR Y
We present the first 3 months of aftershock activity following the 2015 April 25 Gorkha earthquake $M_{\mathrm{w}} 7.8$ recorded on the Nepalese Seismic network. We deployed an automatic procedure composed of three main stages: (1) coarse determination of the $P$ and $S$ onsets; (2) phase association to declare events and (3) iterative addition and refinement of onsets using the Kurtosis characteristic function. In total 9188 events could be located in the Kathmandu region with the majority having small location errors $(<4.5,9$ and $10 \mathrm{~km}$ in the $X$-, $Y$ - and $Z$-directions, respectively). Additionally, we propose a new attenuation law to estimate local magnitudes in the region. This new seismic catalogue reveals a detailed insight into the Gorkha aftershock sequence and its relation to the main shock rupture models and tectonic structures in the region. Most aftershocks fall within the Main Himalayan Thrust (MHT) shear zone or in its hangingwall. Significant temporal and lateral variations of aftershocks location are observed among them: (1) three distinct stages, highlighting subsequent jump-offs at the easternmost termination, (2) the existence of a seismic gap north of Kathmandu which matches with a low slip zone in the rupture area of the main shock, (3) the confinement of seismic activity in the trace of the May $12 M_{\mathrm{w}} 7.3$ earthquake within the MHT and its hangingwall through a $30 \times 30 \mathrm{~km}^{2}$ region and (4) a shallow westward-dipping structure east of the Kathmandu klippe. These new observations with the inferred tectonic structures at depth suggest a tectonic control of part of the aftershock activity by the lateral breaks along the MHT and by the geometry of the duplex above the thrust.
\end{abstract}

Key words: Asia; Computational seismology; Earthquake source observations; Seismicity and tectonics; Crustal structure.

\section{INTRODUCTION}

On 2015 April 25, at 06:11:26 UTC, the Gorkha earthquake ( $\left.7.8 M_{\mathrm{w}}\right)$ struck the main thrust interface between the Indian and Eurasian plates beneath Nepal. The epicentre was located $\sim 75 \mathrm{~km}$ WNW of the capital city Kathmandu, with a hypocentral depth of $\sim 15 \mathrm{~km}$. The main shock partially ruptured a $\sim 120 \mathrm{~km} \times 80 \mathrm{~km}$ patch of the shallow dipping Main Himalayan Thrust (MHT; e.g. Avouac et al. 2015; Galetzka et al. 2015; Grandin et al. 2015; Elliott et al. 2016). The MHT marks the plate boundary between India and the Tibetan Plateau and accommodates most of the Himalayan shortening (e.g. Bettinelli et al. 2006). The rupture propagated eastwards for about 45-50 s with an average rupture speed of $2.8-3.3 \mathrm{~km} \mathrm{~s}^{-1}$ and a maximum slip of $\sim 7 \mathrm{~m}$ (Avouac et al. 2015; Grandin et al. 2015). The main shock and the thousands of aftershocks occurring at mid- crustal depths (Adhikari et al. 2015; Bai et al. 2016) resulted in significant structures damages and fatalities $(8800+)$ in Kathmandu and its nearby region.

On 2015 May 12 (17 days after the main shock), at 07:05:19 UTC, an $M_{\mathrm{w}} 7.3$ aftershock occurred at the eastern termination of the Gorkha rupture, with a hypocentral depth of $\sim 19 \mathrm{~km}$. This earthquake ruptured a $\sim 30 \times 30 \mathrm{~km}^{2}$ patch of the MHT with a maximum slip of $\sim 4 \mathrm{~m}$ (Grandin et al. 2015). The easternmost extent of the patch corresponds to the limit of the 1934 M 8.2 Bihar-Nepal earthquake rupture (Sapkota et al. 2013).

Although multiple studies on the Gorkha earthquake and its aftershock sequence have been published so far none of them contain a complete and robust earthquake catalogue covering the 3 months of local seismic monitoring following the Gorkha earthquake on 2015 April 25. Such a catalogue is essential to better understand the 


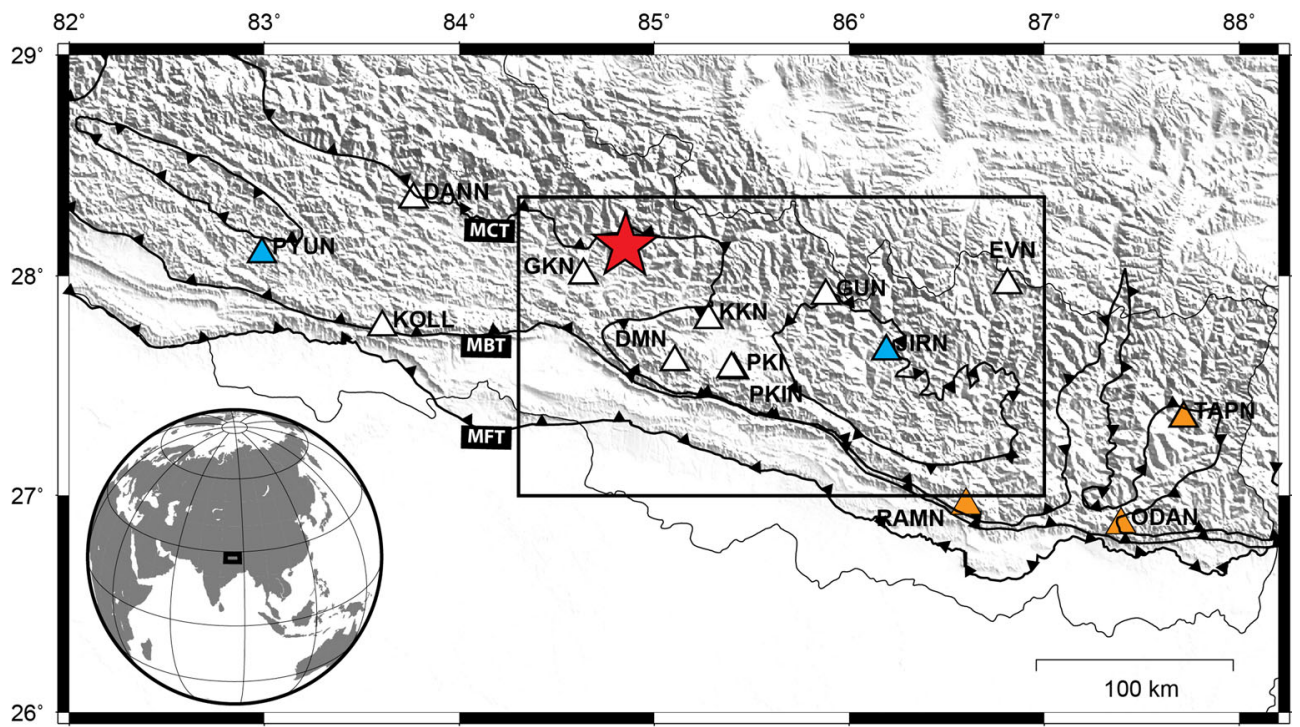

Figure 1. Map of the National Seismological Center of Nepal (NSC) network and Everest station (EVN, triangles). Orange triangles indicate instruments that were unusable until 2015 June 1. Blue triangles indicate instruments with high noise level. Red star indicates the position of the April 25 main shock (7.8 $M_{\mathrm{w}}$ ). The rectangle indicates the region of interest in this study. MFT: Main Frontal Thrust; MBT: Main Boundary Thrust and MCT: Main Central Thrust.

main shock rupture process and its relationship with the surrounding tectonic structures.

Here, we apply for the first time a fully automated procedure, that is, automatic onset determination (Baillard et al. 2014, 2015; Hibert et al. 2014), phase association, location and onset refinement, to the 3 months of continuous seismic data from the National Seismological Center of Nepal (NSC). Such automatic procedures become essential to digest and process the always greater amount of data recorded around the world. Moreover, automatic procedures offer great reliability and consistency over time as they do not depend on human analyst criteria (Freedman 1966; Zeiler \& Velasco 2009). Nowadays, the ability of automatic procedures to detect and determine precisely one single onset has been widely proved (Nippress et al. 2010; Bear \& Kradolfer 1987; Küperkoch et al. 2010). In this paper, we rather put emphasis on the ability of the procedure to iteratively improve the location solution by adding more and more phases to the solution, decreasing considerably location errors (e.g. Rietbrock et al. 2012). Using this procedure, we determine in this paper a new revisited automatic catalogue for the Gorkha earthquake aftershocks, evaluating its reliability regarding other published catalogues, and define new attenuation parameters for the local magnitude computation.

Based on this catalogue, we present in detail the spatiotemporal distribution of the seismic activity. We also discuss the seismic activity in relation with the position of the MHT, the earthquake rupture models and the major tectonic structures in the region.

\section{DATA PRESENTATION}

We focus our analysis on approximately 3 months of data from the 2015 April 25 Gorkha main shock to the 2015 July 31 recorded at the NSC network (Fig. 1). During this period, the permanent seismological network was operational in central and eastern Nepal and consisted of 13 short-period vertical component seismometers (ZM500 $f_{\mathrm{c}}=1 \mathrm{~Hz}$ ) complemented by one three-component seismometer (PKIN). All instruments are recording with one low-gain and one high-gain channel. Out of these 13 instruments, three were unusable from 2015April 28 to June 1 (TAPN, RAMN and ODAN) and two were barely usable due to high noise level (PYUN and JIRN). To increase the NSC network coverage in the northeastern region, we added the Everest three-component broad-band seismometer (IO.EVN IRIS) to our data set. EVN station started to be operational on 2015 April 27, that is, two days after the main shock.

\section{METHODOLOGY}

\subsection{Automatic onset determination and location of events}

The automatic location of events follows a two-step procedure: (1) detection and preliminary location of events on continuous streams, and (2) onset refinement of onsets around theoretical arrival times and relocation of events.

In the first stage, we need to determine potential onsets on continuous data streams and the detection and preliminary location is performed through the Seiscomp3 suite (Weber et al. 2007). We apply to each stream a classical short-term average over long-term average (STA/LTA) filter to roughly detect all potential $P$ onsets (Allen 1982). These first $P$ detections are refined using the Akaike's Information Criterion filter (Akaike 2011). Once the $P$ onsets are determined, the same approach is applied to determine $S$ onsets, adding a priori information that the $S$ onset should be contained in a $20 \mathrm{~s}$ window following the $P$ onset, in order to consider onsets only generated by local and regional events. Each potential onset needs to pass a signal over noise ratio (SNR) test to be considered. At that point, we have at our disposal a set of $P$ and $S$ onsets for each stream.

In the next step, we associate onsets to actual seismic events. It is of major importance to remove falsely identified arrivals generated by noise and to distinguish between seismic events whose respective phase arrivals are close to each other and consistent with a potential earthquake source. The phase association process used in Seiscomp3 is based on a clustering algorithm (Weber et al. 2007) and particularly well adapted when dealing with seismic crisis, as for the Gorkha's aftershock sequence. Once a potential onset is registered in the system, it looks for potential neighbourhood onsets that fulfill a user-defined time criterion, computed given an apparent 
(a)

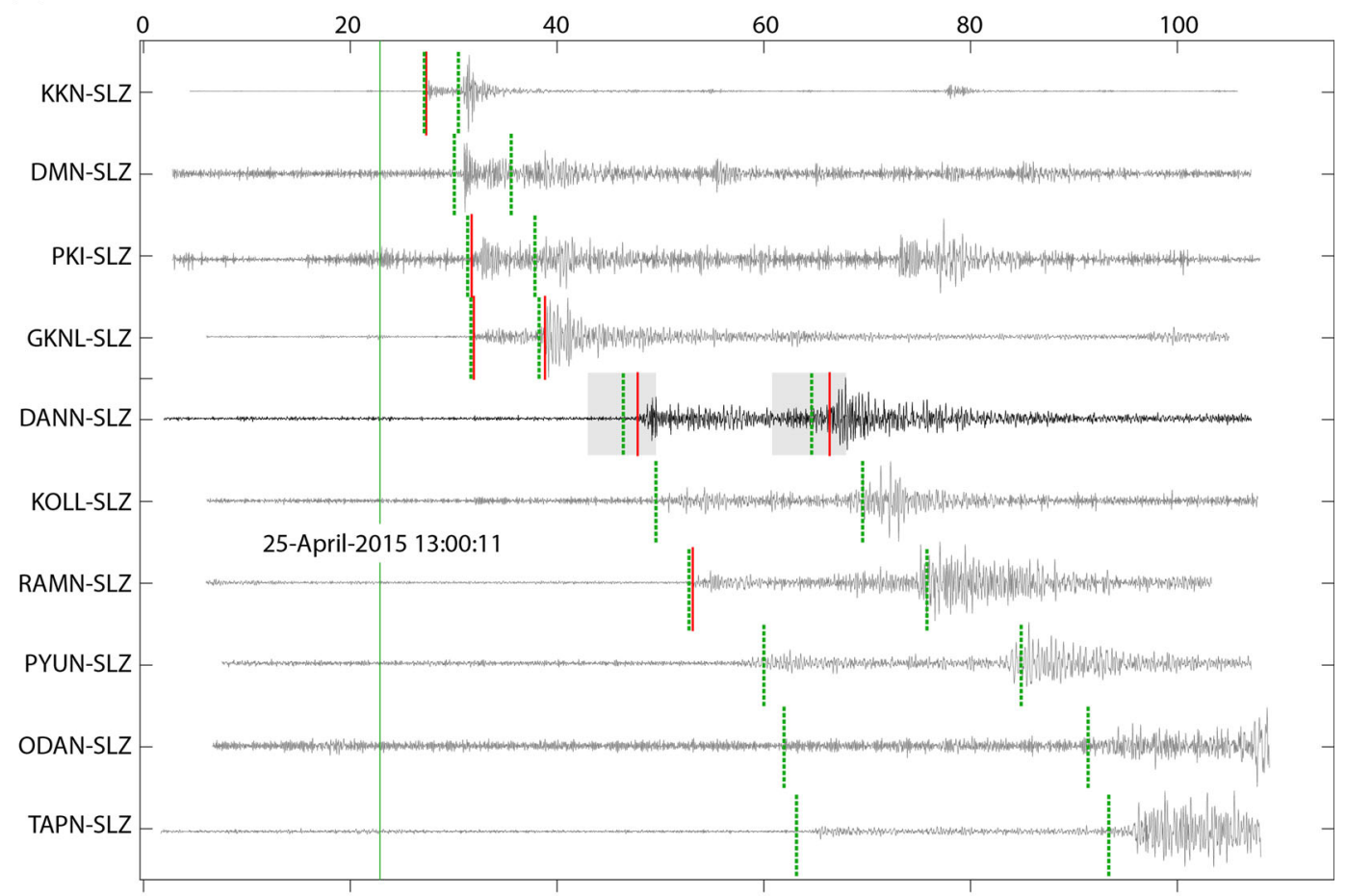

(b)

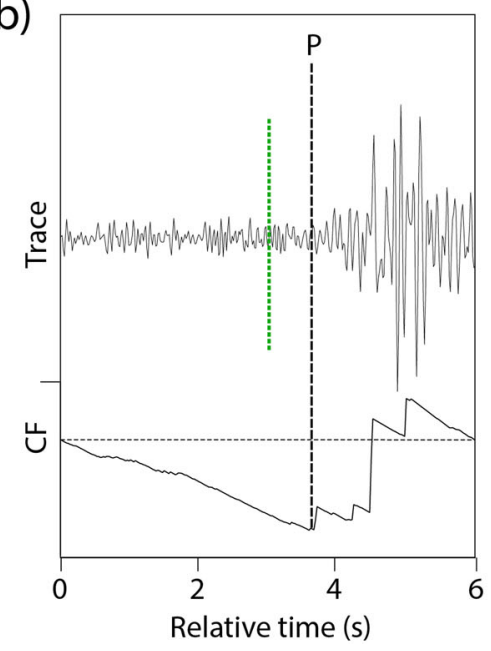

(c)

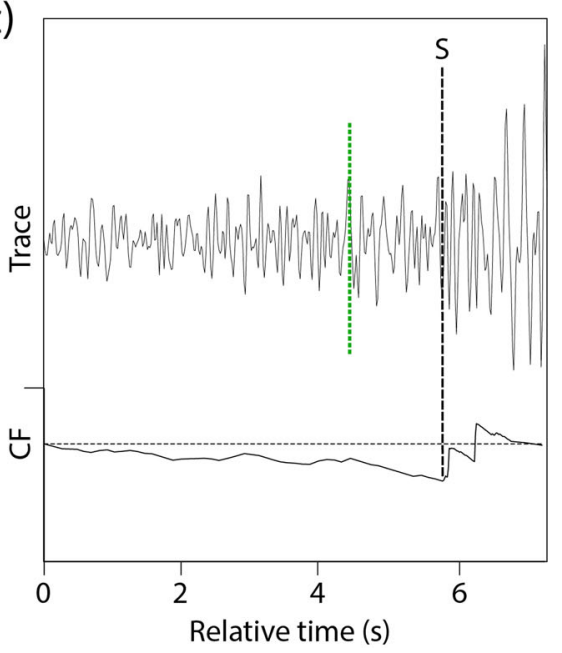

Figure 2. Scheme explaining the automatic refinement procedure. (a) Example of extracted events with a priori origin time (solid green line) and associated theoretical arrival times for $P$ and $S$ phases (dashed green line). Solid red lines indicate onset times before refinement procedure. (b) and (c) show zooms around $P$ and $S$ arrival times associated to trace DANN-SLZ. The Kurtosis characteristic function (CF) is drawn below traces. Minima of the CF indicate the newly refined automatic onsets drawn as dashed black lines.

phase velocity. Once a consistent cluster of onsets is defined, a first location is made and all subsequent phase arrivals are compared to their theoretical arrival times. If the difference between the theoretical and automatic arrival times is sufficiently small, the new phase is associated to that event and so on. At this point, we have a set of events with preliminary locations and associated automatic phases. We call this catalogue the detection catalogue which is composed of 14158 events.

In the second stage, we refine the onset times of the detected phases to improve the location accuracy. This refinement includes both a more accurate onset time determination, using the Kurtosis method (Saragiotis et al. 2002; Baillard et al. 2014, 2015; Hibert et al. 2014) and the detection of onsets that have been ignored or mistakenly dismissed during the phase association process. The workflow used in this refinement process includes three main steps: (1) we compute the theoretical arrival times of $P$ and $S$ waves at each station for one given event using the velocity model of Pandey et al. (1995, 1999). (2) We define time windows around these theoretical arrival times on which we apply the Kurtosis filter developed in Baillard et al. (2014) to determine accurately the arrival times of $P$ and $S$ waves (Fig. 2). The weight of each onset is meant to follow the hypo71 nomenclature and is based on the Kurtosis characteristic function, for example, clear onsets with high Kurtosis will be declared as high-quality onsets (noted 0 ) which mean maximum weight in the inversion. (3) We remove falsely identified phases using a Jackknife resampling analysis (Efron 1982). Our analysis 
Table 1. Statistics of the pre- and post-refinement catalogues. The total number of events includes only events that have observations on five stations or more. The bold numbers indicate the median number of phases per event.

\begin{tabular}{lccrl}
\hline & & Pre-refinement catalogue & \multicolumn{2}{c}{ Post-refinement catalogue } \\
\hline Total number of events & & 7039 & 9188 & $(+31$ per cent $)$ \\
Total number of picks & $P$ & $42917(\mathbf{6})$ & $54136(7)$ & $(+26$ per cent $)$ \\
& $S$ & $23686(3)$ & $50726(6)$ & $(+114$ per cent $)$ \\
\multirow{2}{*}{ Median location error $(\mathrm{km})$} & $Y$ & 13.3 & 3.3 & $(-75$ per cent $)$ \\
& $X$ & 20.9 & 7.4 & $(-64$ per cent $)$ \\
& $X$ & 32 & 10 & $(-69$ per cent $)$ \\
\hline
\end{tabular}

consists in computing the location of an event by removing one onset at a time from the initial set of onsets. Each time an onset is removed, the location residual is computed. We remove the onsets that drastically worsen the residual value, that is, residuals that lie above three standard deviations from the median residual.

Steps (1)-(3) are repeated iteratively (the number of successive iterations is a user-defined parameter) to obtain the final location of the events. Typically, for one event of our data set the computation time is less than $5 \mathrm{~s}$ per event.

Table 1 summarizes the result of the two-stage automatic procedure described above and compares the pre- and post-refinement catalogues. To insure a consistent comparison, these catalogues are a selection of the detection catalogue, where events have observations on at least five stations and are located inside the network $\left(83^{\circ} \mathrm{E}-88^{\circ} \mathrm{E} / 26.5^{\circ} \mathrm{N}-28.5^{\circ} \mathrm{N}\right)$.

\subsection{Error estimates and comparison to the manual catalogue}

To check the reliability of the automatic post-refinement catalogue, we analysed the standard location errors given by hypo 71 of 9188 events (Fig. 3). The errors are rather low, especially horizontally, with errors $<4.5$ and $<9 \mathrm{~km}$ in the $X$-and $Y$-directions, respectively, for 68 per cent of the events. The fact that the error is larger in the $Y$-direction comes from the west-east elongation of the network. Errors associated with depths are $<10 \mathrm{~km}$ for 68 per cent of the events. This error is related to the interstation distance $(\sim 50 \mathrm{~km})$ and to the west-east extent of the network reaching $\sim 500 \mathrm{~km}$.

Another way to check the reliability of the automatic procedure is to compare the automatically obtained locations to the manual locations published by Adhikari et al. (2015). Events listed in the manual catalogue were obtained by determining the onsets of arrivals by an analyst and spans the period of 45 days after the April 25 main shock, until June 8 . For the same period, the manual catalogue is composed of 4401 events, whereas the new catalogue contains 7426 events. Therefore, the detection rate has thus been increased by a factor 1.7 without altering the location quality.

Events from the manual catalogue were initially located using classical inversion and were relocated using ISC locator (Bondar \& Storchak 2011). The manual catalogue contains 554 events with NSC local magnitudes $>4$. When comparing the automatic catalogue and the manual catalogue, we identified 270 common events out of 554 (48 per cent). A large part of the missing events in the automatic catalogue occurred for two hours after the April 25 main shock and the May 12 aftershock $\left(7.3 M_{\mathrm{w}}\right)$. By removing the events occurring during these two days, we could extract 200 common events out of 334 (60 per cent). We reviewed manually the missing events, the reasons why the automatic procedure failed to locate these events are (1) the very low SNR for some events, (2) the
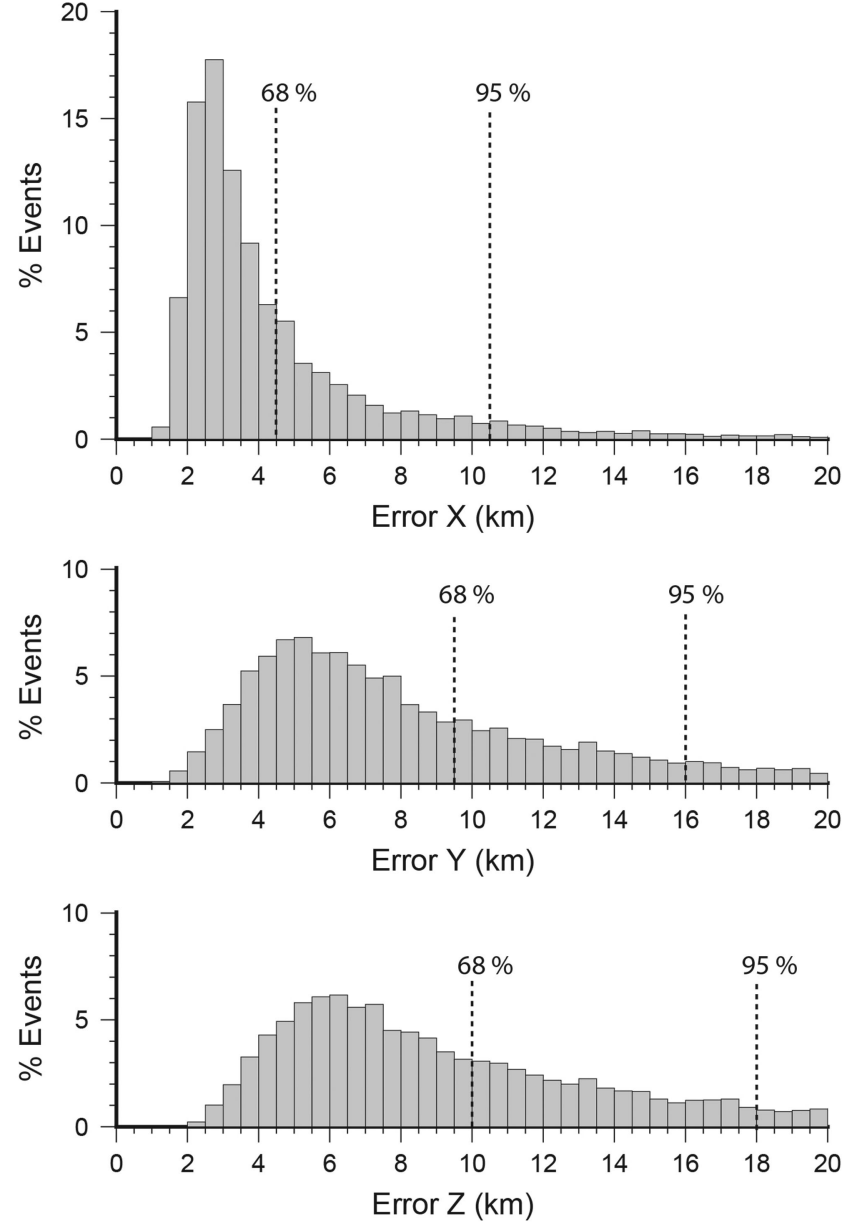

Figure 3. Location error estimates of the post-refinement catalogue ( 9188 events). Top to bottom figures indicate errors in the $X$-, $Y$ - and $Z$-directions. Note the larger epicentre errors in the $Y$-direction due to the W-E extended shape of the network.

repeated clipping of both our low- and high-gain traces during the strongest shocks, (3) the presence of nested events that are considerably reducing the efficiency of the automatic procedure (see Fig. S1, Supporting Information to see the influence of closeby events on the detection capacity of the automatic procedure) and (4) the different methodologies used for the inversion of the first arrivals.

Considering the 270 common events, the difference in locations between the manual and the automatic catalogues is small (Fig. 4). The difference is generally less than 2 and $6 \mathrm{~km}$ in the horizontal and vertical directions, respectively. 


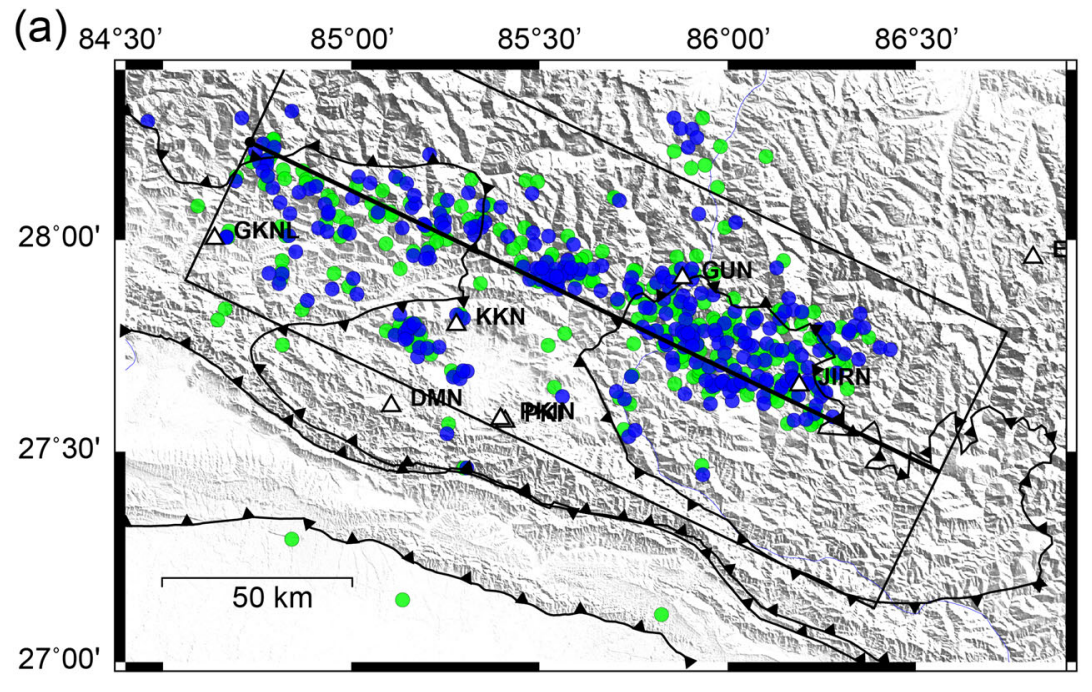

(c)
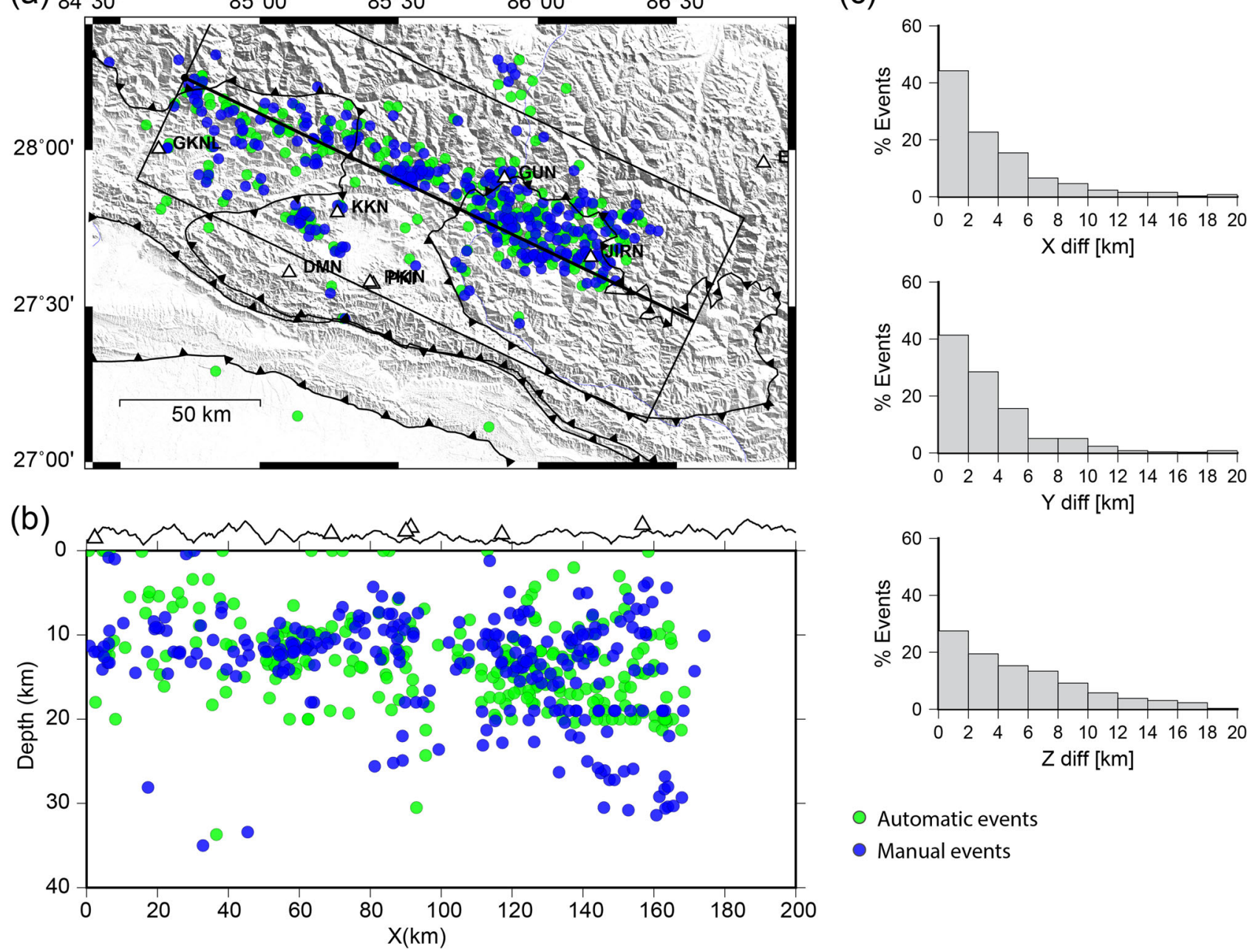

Automatic events

- Manual events

Figure 4. Location comparison between the manual and the automatic catalogues for the 270 common events of $M_{\mathrm{L}}>4$. (a) Map view of manual (blue circles) and automatic locations (green circles). (b) Cross-section showing locations projected onto an N110 profile. (c) Histograms showing absolute location differences between the two catalogues.

The small location uncertainties of the automatic catalogue and its consistency with the manual catalogue demonstrate the reliability of our newly improved automatic procedure.

\subsection{Magnitude calculation}

It has been noted before the Gorkha earthquake that the local magnitude $\left(M_{\mathrm{L}}\right)$ reported by NSC is significantly larger than the $m_{\mathrm{b}}$, $M_{\mathrm{s}}$ and $M_{\mathrm{w}}$ (Rajaure et al. 2011). To rectify this and help with comparison in the future, we propose a new $M_{\mathrm{L}}$ on the $m_{\mathrm{b}}$. The magnitude calculation is performed automatically. The calculation is performed on (2 to $15 \mathrm{~Hz}$ ) bandpass filtered seismograms and based on the zero-to-peak maximum amplitude of the $S$ wave (Havskov \& Ottemoller 1999). We look for the maximum amplitude in a time window around the theoretical arrival time of the $S$ wave. To reject anomalous amplitude measurements, we make the assumption that for the same event, each station should have more or less the same magnitude considering a simple attenuation law. Potential magnitudes that do not fall into the range median $M_{\mathrm{L}} \pm 0.8 M_{\mathrm{L}}$ are rejected. The final magnitude for a single event is obtained by averaging the remaining magnitudes. Magnitudes are computed for all events of our post-refinement catalogue.
We used our amplitude measurements to find a new attenuation law for the central Nepal region as the current one is not adapted to the region. The formula we use to calculate local magnitude is:

$M_{\mathrm{L}}=a \times \log _{10} A+b \times \log _{10} D+c \times D+d$

where $A$ is the zero-peak amplitude in nanometres, $D$ is the distance from hypocentre to station in kilometres and $a, b, c$ and $d$ are constants we want to determine (Havskov \& Ottemoller 1999). To achieve this, we compared local magnitudes obtained automatically to $m_{\mathrm{b}}$ magnitudes coming from the National Earthquake Information Center (NEIC) catalogue. For the 3 months observation period, we found 137 common events for which the magnitude could be compared (Fig. 5). The $m_{\mathrm{b}}$ range of events that are compared is between 3.4 and 5.5. No events with $m_{\mathrm{b}}>$ 5.5 could be compared because of the clipping of the seismograms for the range of epicentral distances considered. First, we determine a linear regression equation relating $M_{\mathrm{L}}$ to $m_{\mathrm{b}}$. Second, we correct the $M_{\mathrm{L}}$ values assuming, that $M_{\mathrm{L}}$ is equal to $m_{\mathrm{b}}$ for the range of magnitudes we are studying and for shallow events (Kanamori 1983; Ristau 2009) and calculate the associated regression equation. 


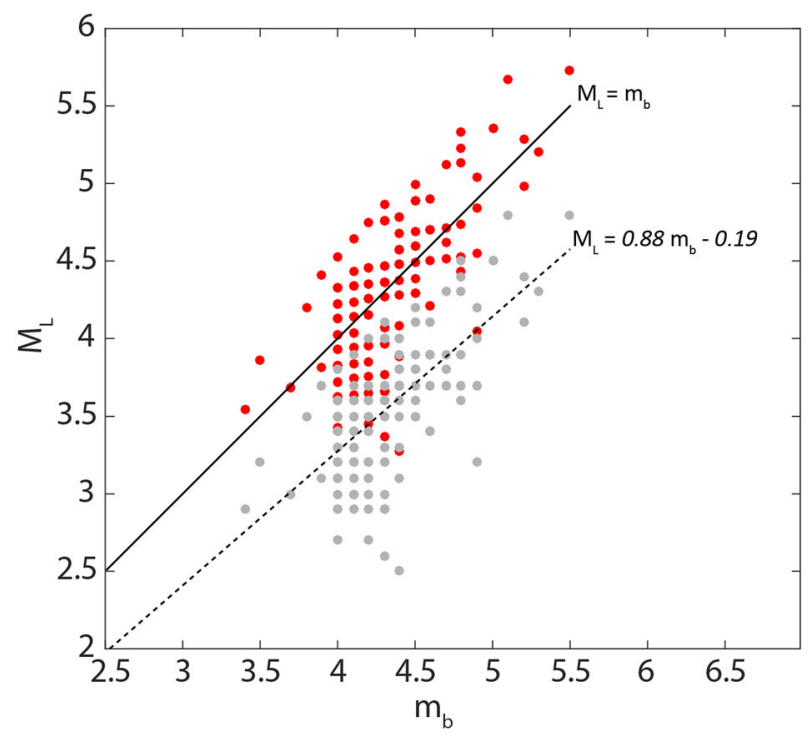

Figure 5. Local magnitude calibration using 137 common events taken from the NEIC catalogue and ours. Grey circles indicate $M_{\mathrm{L}}$ versus $m_{\mathrm{b}}$ events relation before calibration. Dashed black line shows the linear regression equation found. Red circles indicate $M_{\mathrm{L}}$ versus $m_{\mathrm{b}}$ events after calibration.

After calibration of the local magnitudes $M_{\mathrm{L} / \mathrm{obs}}$ with respect to the $m_{\mathrm{b}}$ magnitudes, we constrain the four constants $(a, b, c$ and $d)$ of the local magnitude equation adopting a grid-search approach, that is, computing the local magnitudes $M_{\mathrm{L} / \mathrm{cal}}$ for each set of parameters. The range of parameters tested are as follows: $a=(0.51 .5)$, $b=\left(\begin{array}{ll}0.5 & 1.5\end{array}\right), c=\left(\begin{array}{ll}0 & 0.006\end{array}\right)$ and $d=\left(\begin{array}{ll}-2.5 & 0.5\end{array}\right)$. The total number of combinations tested is $20^{4}$. Finding the minimum residual (root-mean-square error), $\left|M_{\mathrm{L} / \mathrm{obs}}-M_{\mathrm{L} / \mathrm{cal}}\right|=0.175$ leads to the following local magnitude equation for central Nepal:

$M_{\mathrm{L}}=0.9 \times \log _{10} A+1.2 \times \log _{10} D+0.0003 \times D-0.9$.

\section{RESULTS}

We previously demonstrated the robustness of our catalogue regarding location errors and detection rate. However, as stated before, some events are missing in our catalogue due to clipping, nested early aftershocks and low SNR of the traces after important shocks, which lower the detection rate.

To construct the most complete seismic catalogue for the time span following these large earthquakes, we integrated 76 events of the ISC locator catalogue into our automatic catalogue. In practice, these 76 events replaced $2 \mathrm{hr}$ of data from our catalogue just after the three main shocks $\left(M_{\mathrm{w}}>6\right): 7.8 M_{\mathrm{w}} 2015$ April $2506: 11$ (now referred as E1); 6.7 $M_{\mathrm{w}} 2015$ April 26 07:09 (E2) and 7.3 $M_{\mathrm{w}}$ 2015 May 12 07:05 (E3). When possible, we manually repicked 38 events of the 76 events declared in the ISC locator catalogue to improve the locations. This procedure increases the number of events in the catalogue from 9188 to 9234 . Fig. 6 shows the detection rate, the distribution of magnitudes in time and the cumulative seismic moment $M_{0}\left(\log M_{0}=1.5 M_{\mathrm{w}}+16.1\right.$, after Kanamori (1983), when no $M_{\mathrm{w}}$ is available we assume $M_{\mathrm{w}}=M_{\mathrm{L}}$ in the formula). The minimum magnitude of completeness of the catalogue $\left(M_{\mathrm{C}}\right)$ is estimated to be around 2.5 in $M_{\mathrm{L}}$ (Fig. 7; see Section 5) and the $b$-value is estimated to be around $0.92 \pm 0.05$. The magnitude of completeness of the catalogue is one order lower than the one estimated by Adhikari et al. $\left(2015 ; M_{\mathrm{C}} \approx 4\right)$. The $b$-value we found $(b=0.92)$
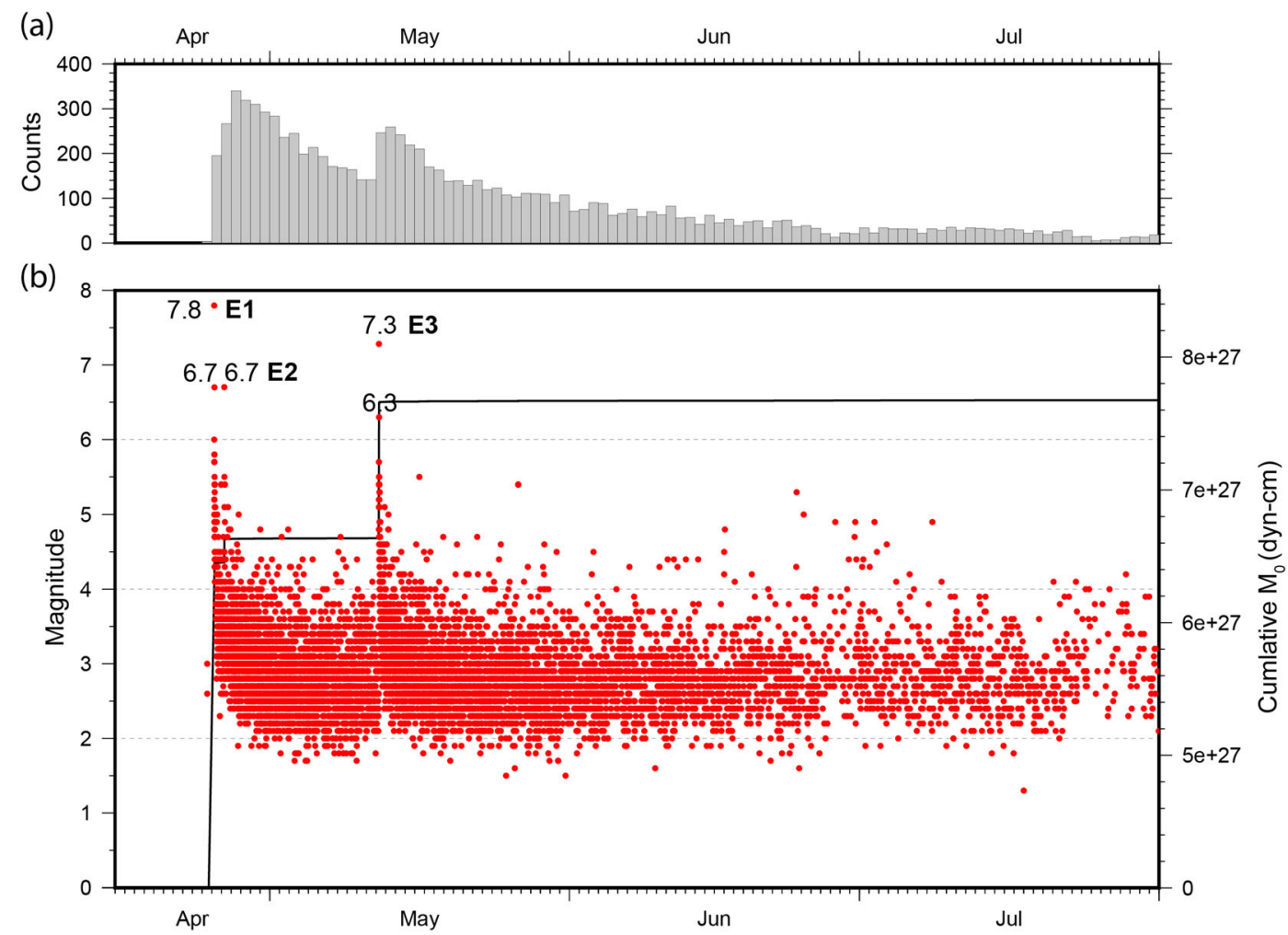

Figure 6. Magnitudes and time distribution of the 9234 events of the local catalogue. (a) Daily seismic rate, note the decrease of seismicity right after E3 earthquake. (b) Distribution of events with time. Magnitudes $>6$ are taken from the USGS catalogue. Solid black line indicates the cumulative seismic moment $M_{0}$ of the local catalogue. 


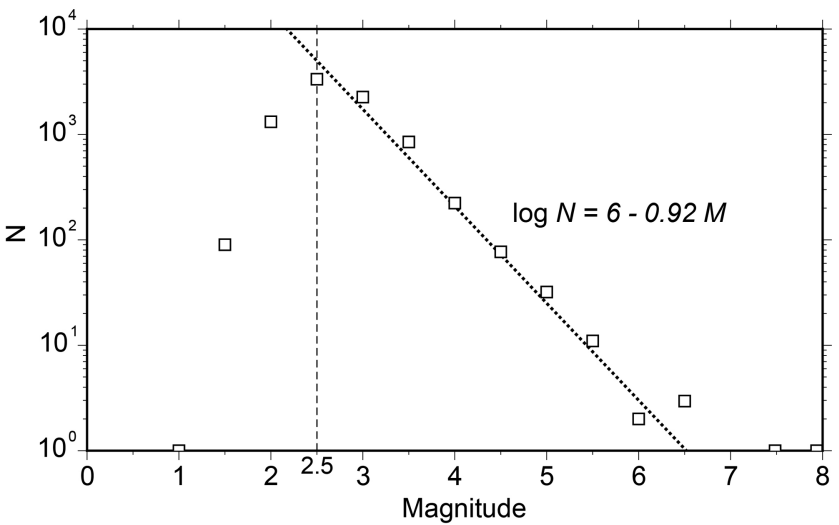

Figure 7 Gutenberg-Richter plot of the local catalogue. Dashed line points the estimated magnitude of completeness $\left(M_{\mathrm{C}}=2.5 M_{\mathrm{L}}\right)$. The dotted line represents the linear portion of the catalogue. $b$-value is estimated around 0.92 .

is higher than the one found by Adhikari et al. (2015) and McNamara et al. $(2016 ; b=0.80)$ but is closer to the global average $(b=1.0)$. The differences in $M_{\mathrm{C}}$ shows the capacity of the automatic procedure to detect a more complete range of earthquakes with $M_{\mathrm{L}}>M_{\mathrm{C}}$. The higher $b$-value we obtained might be related to the integration of small earthquake swarms that lack of major earthquakes.

The final earthquake catalogue is shown on Fig. 8. The profile plots integrate the presumed geometries of the MHT inferred from the inversion of the Gorkha earthquake (Grandin et al. 2015; Elliott et al. 2016) and receiver-function analysis (Duputel et al. 2016). All three geometries are relatively similar with small dipping angles in the flat portion of the MHT (between $1^{\circ}$ and $8^{\circ}$ ) and azimuthal directions of $\sim 15^{\circ} \mathrm{N}$. One can note that the flat portion of the MHT geometry taken from Duputel et al. (2016) persists at shallower depth towards north. These observations are also consistent with the geometry proposed by Hubbard et al. (2016) where the rupture of the Gorkha earthquake is bounded by the flat portion of the MHT.

\subsection{Spatiotemporal variation of seismicity and eastward termination}

Most of the seismicity occurring within the first 3 months following the Gorkha earthquake (E1) is confined into a narrow region $200 \mathrm{~km}$ long and $70 \mathrm{~km}$ wide. The temporal distribution of seismicity projected onto profile 5 as a function of distance (Fig. 9) indicates that the microseismicity is distributed almost homogeneously along the section and is sustained continuously over time. There is no clear overall migration of seismicity in the east-west direction, except at the easternmost part. Three stages in time can be observed in the evolution of the aftershock sequence (Fig. 10). First, when taking a closer look at the aftershock sequence occurring the day of E1 we see a clear stop of the activity $140 \mathrm{~km}$ eastward from E1. In the period between time E2 and E3, we observe a progressive migration of activity towards the east (Figs 9 and 10) with an offset of about $10 \mathrm{~km}$ of the seismic termination of activity. Then, finally, E3 and its sequence mark a clear and sudden migration of the seismic activity with a jump-off in respect of the termination of almost $25 \mathrm{~km}$. Eastwards of this termination, the lack of seismicity is striking and is sustained until the end of July. This termination of seismicity affects all range of depths and is not confined to the MHT shear zone.
Events located less than $\pm 6 \mathrm{~km}$ ( $\sim$ half of the depth uncertainty) from the MHT and events located between the surface and $6 \mathrm{~km}$ above the MHT are considered hereafter as interplate and hangingwall earthquakes, respectively. The seismicity is equally distributed between interplate (3963) and hangingwall (3981) seismicity, which represents $\sim 43$ per cent of the overall seismicity for both types of events.

\subsection{Relation to the April 25 and May 12 rupture models}

We vertically projected the seismicity onto the presumed MHT geometry (Grandin et al. 2015; Elliott et al. 2016) for the seismicity occurring before and after earthquake E3. We then computed density maps for these two periods of time. We define the density as the number of events that falls into a $5 \times 5 \mathrm{~km}$ map bin. Density maps are then compared to slip models of E1 and E3 from Grandin et al. (2015; Fig. 11).

Density maps associated with the two periods of seismicity show overall the same clusters of activity. For the first period of activity E1 $<T<$ E3, we show that the dense seismic activity contours quite well the slip model of E1, especially for the two clusters to the NW and the cluster south of station KKN (later referred as cluster B). However, we see that the long strip of dense activity to the east is not solely restrained to the border of the E1 rupture model but overlaps the portion where large slip was inferred, bearing in mind the possible bias induced by the smoothing of the slip model (Fig. 11a). Although part of that activity can be considered to occur in the hangingwall, an important part of it is probably located on or near the presumed MHT itself. This observation might suggest that locked asperities subsist after E1 rupture and are later released through earthquakes.

For the second period of activity $T>\mathrm{E} 3$, in addition to the clusters described above, we note the high density of activity in the vicinity of the E3 rupture. Again, the seismicity is almost equally divided between hangingwall and MHT seismicity.

To better highlight the seismic activity that might be directly associated to E3, we subtracted the density map before E3 from the density map after E3 (Fig. 11c). The resulting density map does not reveal aftershocks solely triggered by E3 but indicates rather the spatial distribution of the seismic activity after E3. This activity is confined to a narrow region $\left(30 \times 30 \mathrm{~km}^{2}\right)$ that fits well to the dimension of the E3 rupture model (Grandin et al. 2015). The northern and eastern borders of this region coincide with the location of the MCT (Figs 8 and 11).

We also computed $a$ - and $b$-values for subsets of events associated to the E1 and E3 earthquakes (Fig. S2, Supporting Information). For the two subsets of events we selected events that occurred within the $17 \mathrm{~d}$ after E1 and E3. For the latter subset, we only selected events that were located inside a region delimited by the E3 rupture model. We then computed the Gutenberg-Richter parameters for each subset. To allow comparison, we normalized the number of events for the two subsets by the size of the ruptured area $(\sim 7800$ $\mathrm{km}^{2}$ for E1 and $\sim 990 \mathrm{~km}^{2}$ for E3). We show that $b$-values are similar for the two subsets $(\sim 0.8)$ but $a$-values for subset E3 $(\sim 2.0)$ is significantly higher than the one obtained for subset E1 $(\sim 1.2)$.

\subsection{Cluster studies}

Two remarkable clusters of seismicity emerge from the whole aftershock sequence: Cluster A, located to the north close to the $\mathrm{Nepal} / \mathrm{China}$ border and cluster B, located $20 \mathrm{~km}$ westward from 

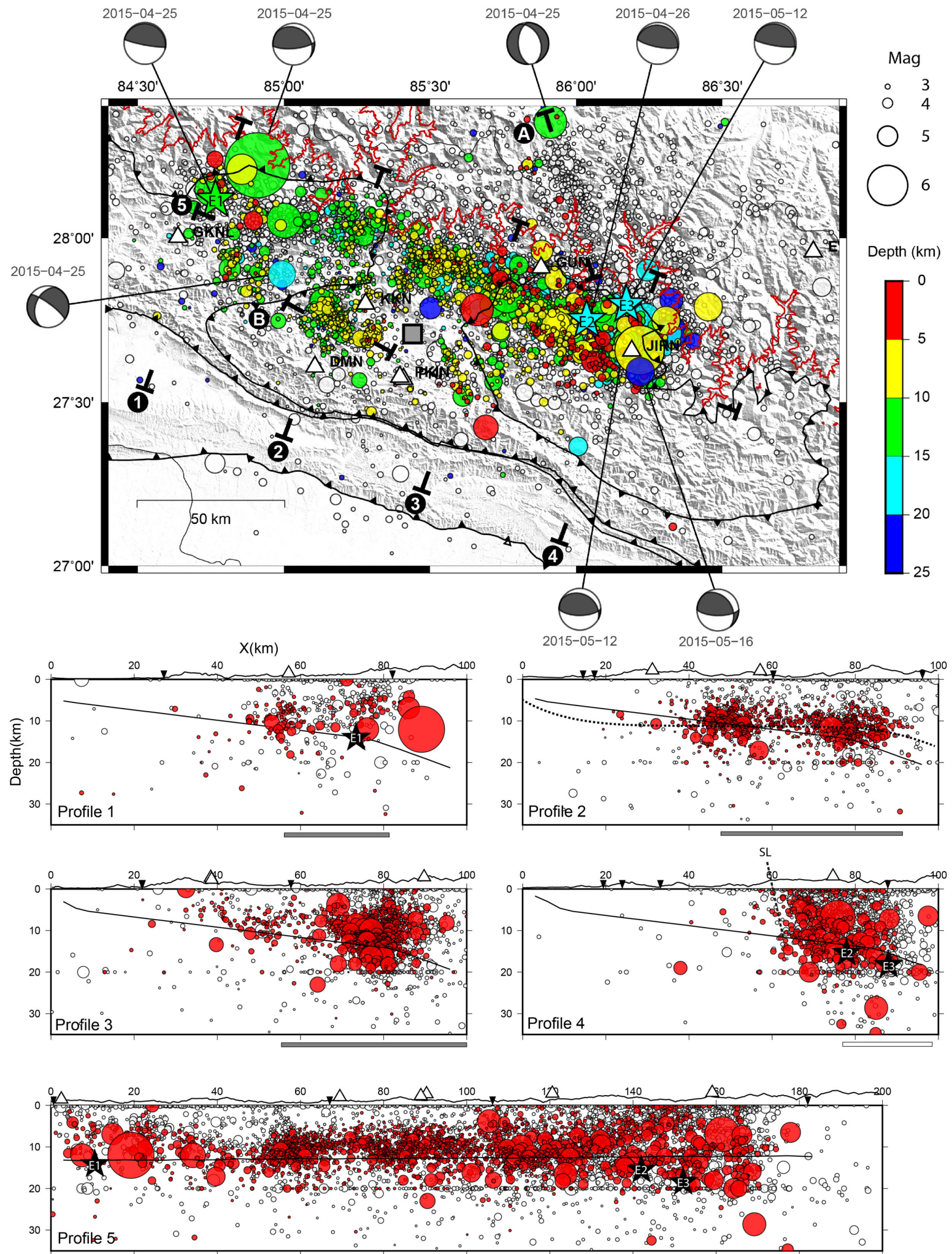

Figure 8. Map and profile views of the Gorkha aftershock sequence. Earthquakes E1, E2 and E3 are represented by stars. Numbers/letters indicate profiles number/letter used in this study. Grey square indicates position of Kathmandu. GCMT focal mechanisms are indicated as grey beach balls. Red circles on cross-sections views highlights a subset of well-located events (2692 events with epicentral errors $<7 \mathrm{~km}$ and depth errors $<10 \mathrm{~km}$ ) from the rest of the catalogue (white circles). Solid black lines indicate the MHT geometry used by Grandin et al. (2015) and Elliott et al. (2016). Dotted black line on profile 2 indicates the MHT geometry according to Duputel et al. (2016). The southern limit of seismicity (SL) is indicated by a dotted black line on profile 4. Inverted black triangles on top of profiles are projection of MCT and MBT faults. Grey and white rectangles at the bottom of profiles are projection of the rupture model of E1 and E3 earthquakes (Grandin et al. 2015). 

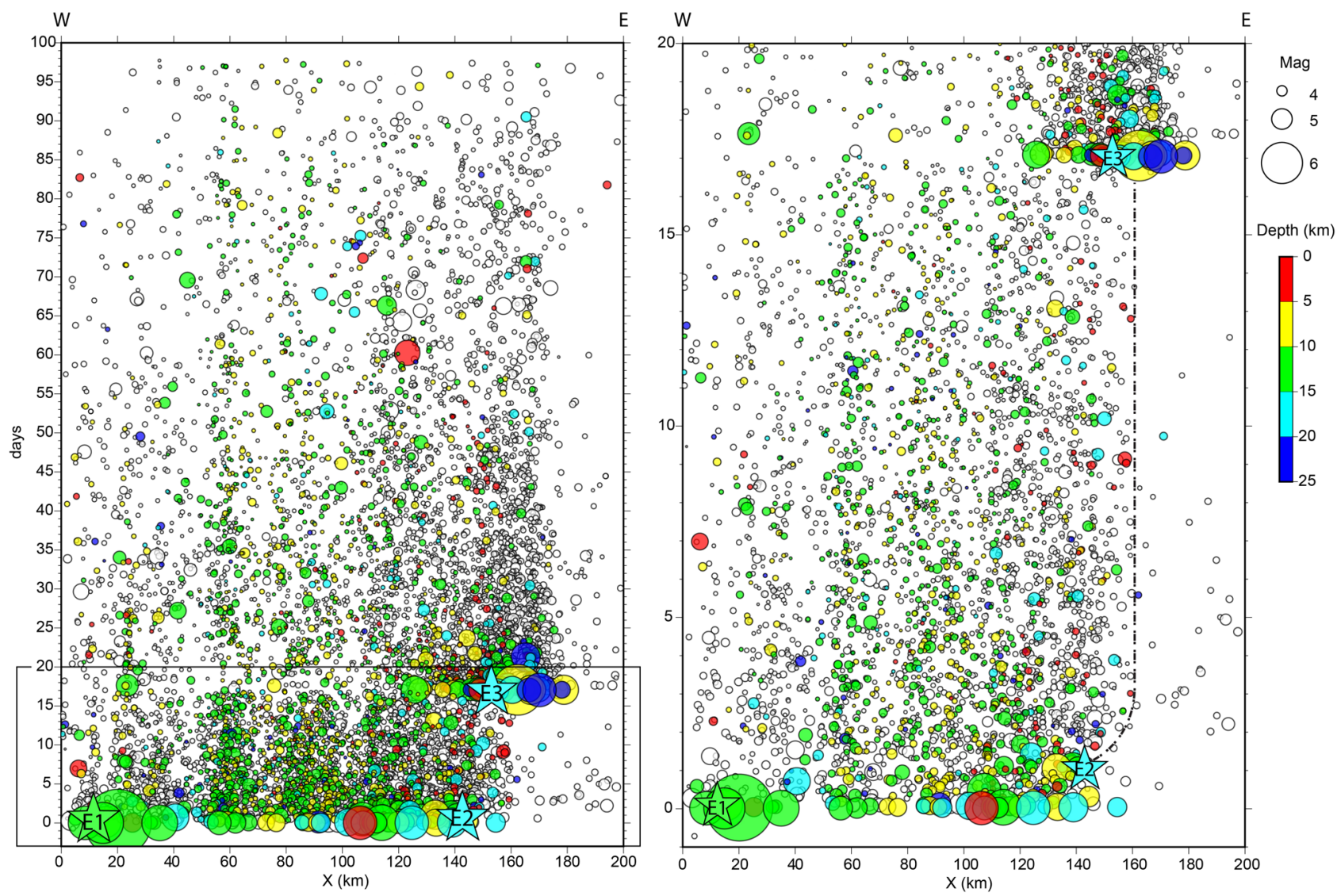

Figure 9. Time distribution of events as a function of distance from E1 along profile 5 (see Fig. 8). Day 0 corresponds to E1 origin time. Right-hand panel is a zoom onto the first $20 \mathrm{~d}$ after E1. Dashed line represents the eastern termination of seismicity following E2. Note the jump-off of seismicity in the eastern region when E3 occurs. Events symbols and colours are identical to the ones of Fig. 8.

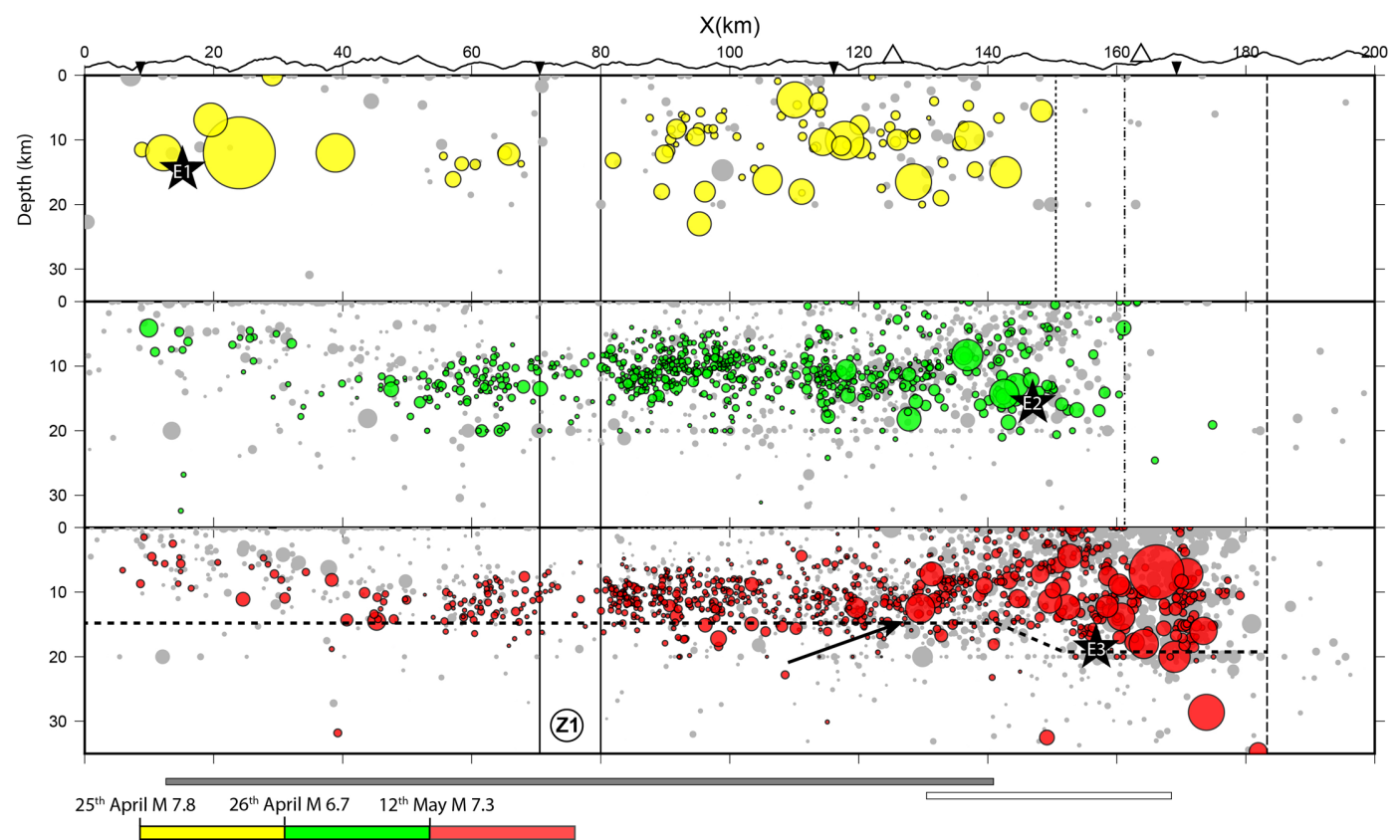

Figure 10. Three stages time evolution of seismicity. Events are projected onto profile 5 (see Fig. 8). Seismicity during period E1 $<T<$ E2 (yellow); E2 $<T$ $<$ E3 (green) and $T>$ E3 (red). Grey circles show locations of events that are less well constrained. Z1 indicates the seismic activity gap. Dashed and dotted vertical lines illustrate migration of the easternmost seismic termination. The black arrow highlights the $18^{\circ}$ west dipping of events. The dashed horizontal line is our interpretation of the downdip limit of seismicity occurring on the MHT. 

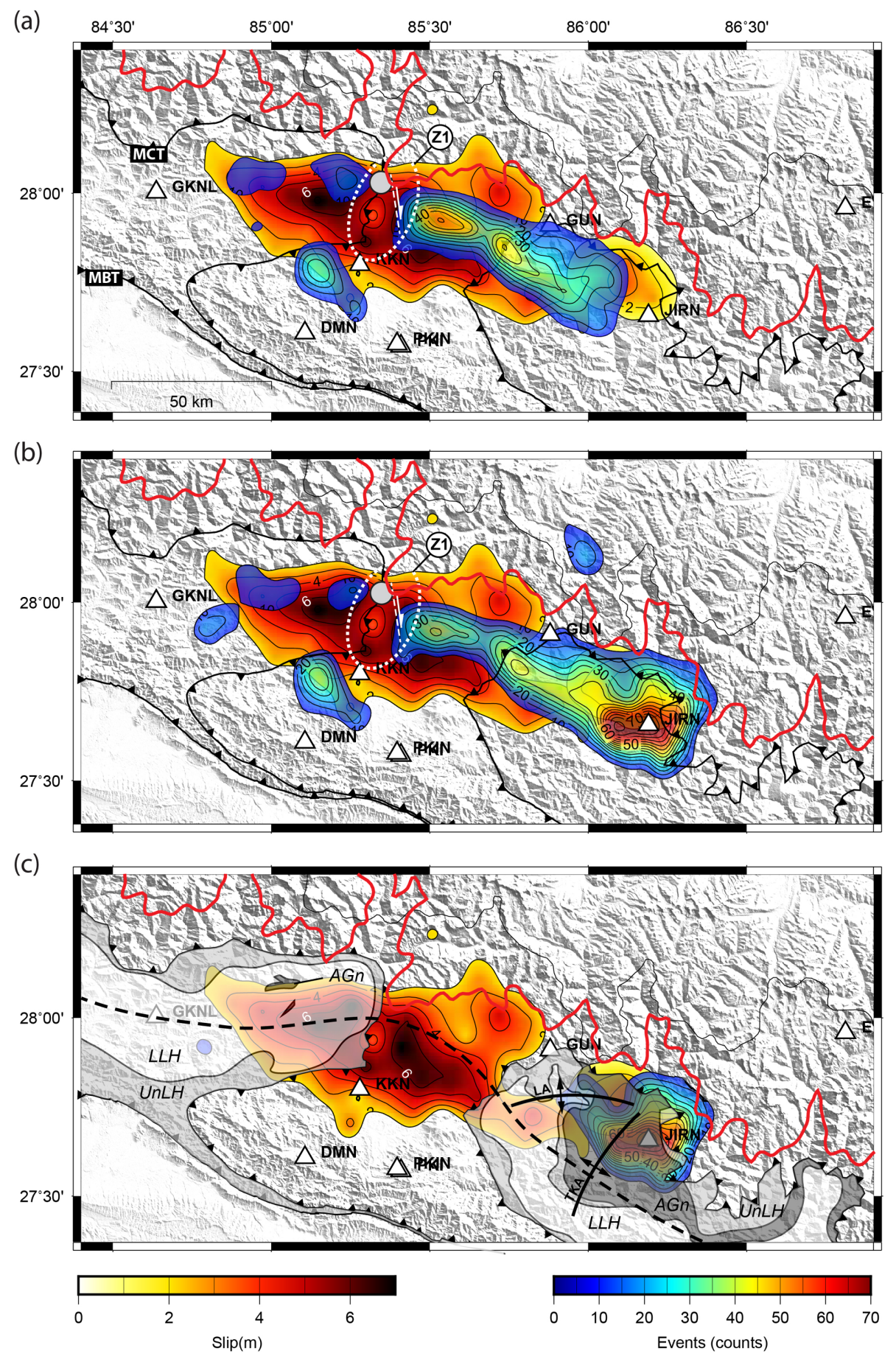

Figure 11. Seismic density maps and relation to the smoothed slip models. The density maps indicate the number of events that fall into a $5 \times 5 \mathrm{~km}$ bin. Red line, location of the $3500 \mathrm{~m}$ contour line which corresponds approximately to the microseismicity cut-off (Bollinger et al. 2004). (a) Seismic density map before E3, dashed white contour indicates the seismic gap zone Z1. The grey circle indicates the position of the 1997 Sarshin earthquake (M 5.8). Dashed white line shows the location of the tear fault proposed by Hoste-Colomer et al. (2016). Warm coloured surfaces indicate the E1 and E3 rupture models. (b) Seismic density map after E3. (c) Subtraction of density map (a) from density map (b). Overlay is the geological map inferred from Schelling (1992). Geological units abbreviations are: LLH: Lower Lesser Himalaya; AGn: Augen Gneisses; UnLH: Undifferentiated lower and upper Lesser Himalaya. Double headed arrows indicate the Lamosangu Antiform (LA) and Tamba Kosi Antiform (TKA). Dashed line indicates the first-order WE nepalese anticlinorium. MBT and MCT same as in Fig. 1.

Kathmandu (see labels A and B in Fig. 8). We focus here on the spatiotemporal distributions of these clusters in the following (Fig. 12).

Cluster A is mostly located outside the seismic network considered, even though epicentres are relatively well constrained, their depth remains uncertain. The apparent south dipping alignment of seismicity (Fig. 12a) is more likely an artefact of location rather than the image of a true structure. The most striking features concerning cluster $\mathrm{A}$ are its continuous extent and its $\mathrm{N} 10^{\circ} \mathrm{W}$ direction similar to the strike of the $5.7 M_{\mathrm{L}}\left(5.3 M_{\mathrm{W}}\right)$ Nyalam normal-fault earthquake that occurred the same day as E1 (Fig. 8). Depth resolution prevents 
(a)
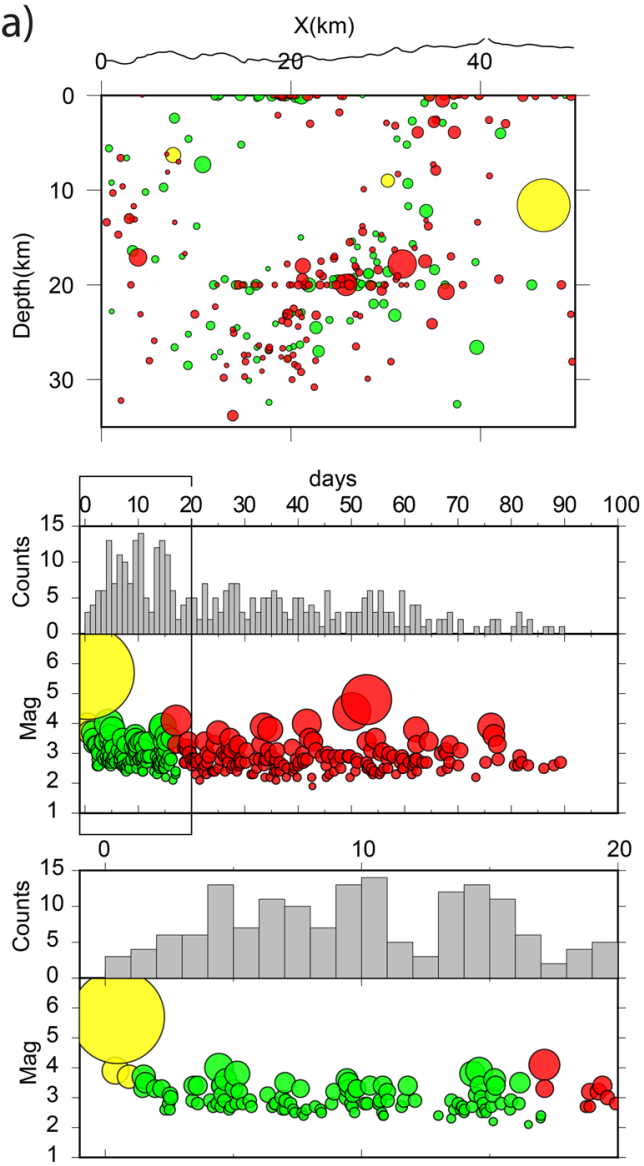

(b)
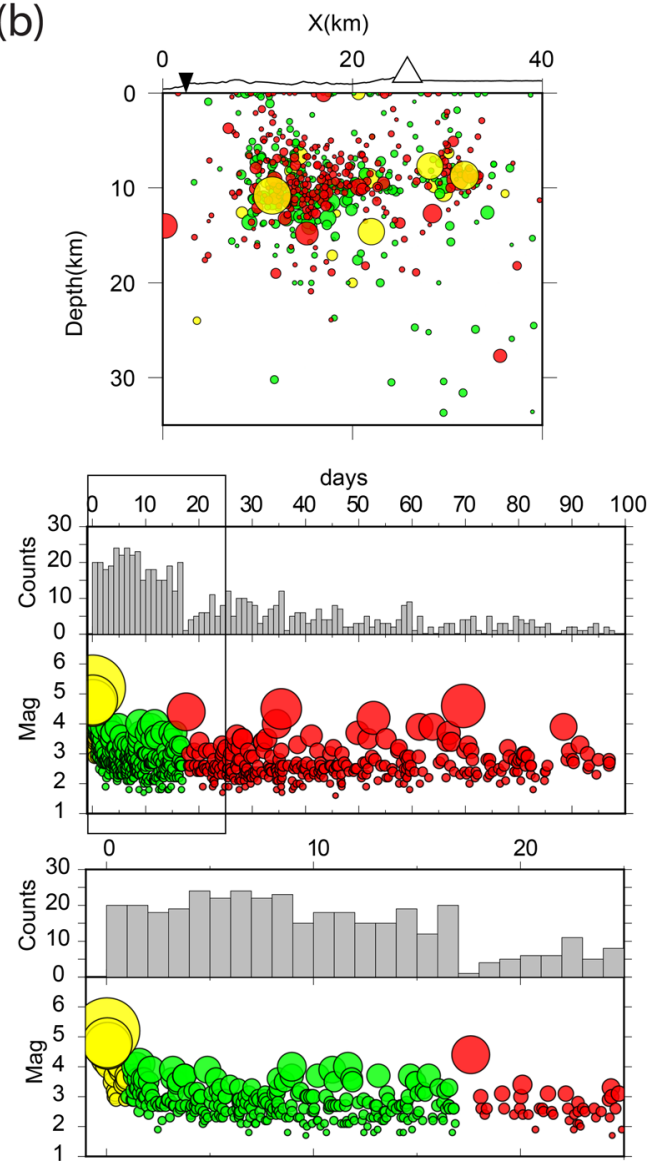

Figure 12. Spatiotemporal distributions of seismic clusters. (a) Top: S-N cross-section (profile A, Fig. 8) showing location of events of cluster A. Middle: time distribution of events associated to cluster A. Bottom: zoom on the drawn rectangle. (b) Top: W-E cross-section (profile B, Fig. 8) showing location of events of cluster B. Middle and bottom same as (a) but for cluster B. Colour scale same as in Fig. 10.

us to look for a correlation between dip of the main earthquake fault plane and a possible alignment of hypocentres. The seismic activity shows no clear spatial migration. The cluster activity started with the $M_{\mathrm{w}} 5.3$ event and decreases progressively with time suggesting a possible aftershock sequence of this event. No sudden reactivation or stopping of its activity are observed during the monitoring time.

Cluster B is better constrained than cluster A as it is located inside our network. When projecting the hypocentres onto a $\mathrm{N} 110^{\circ} \mathrm{E}$ trending profile one can distinguish two subclusters located around $10 \mathrm{~km}$ depth. Taking into account depth uncertainties, cluster B seems to be mainly located onto the presumed MHT. As for cluster A, the seismic activity started just after the main shock and does not show any clear spatial migration. Time evolution of the events in this cluster appears more complex than for cluster A. First, we note a recurrence time of $\sim 20 \mathrm{~d}$ for events $M_{\mathrm{L}}>4$ (Fig. 11b). Second, one of this $M_{\mathrm{L}}>4$ earthquake occurs right after E3 and is followed by a sudden decrease of the recorded seismic rate.

\section{DISCUSSION}

\subsection{Magnitude of completeness}

We emphasize that the attenuation parameters found to build our magnitude law is 1-D. It is certain that the large lateral structural and rheological heterogeneities observed in the region of Kathmandu (e.g. Stocklin 1980) modify the seismic waveforms recorded, especially amplitudes. Comparing our local magnitudes, based on amplitudes, to coda magnitudes would undoubtedly constrain the attenuation law parameters proposed in this study.

However, considering that the local magnitudes of the catalogue are well constrained, one could discuss whether or not the magnitude of completeness $M_{\mathrm{C}}=2.5$ is consistent with the geometry and the sites quality of the NSC network and is not related to the sensitivity of our automatic procedure.

Wiemer \& Wyss (2000) investigated the correlation between density of seismic stations and $M_{\mathrm{C}}$ for two onshore networks. They showed that $M_{\mathrm{C}}$ varies between 2.3 and 2.5 when interstations distance varies between 50 and $70 \mathrm{~km}$ (Californian network). Other factors such as ambient noise level at sites might influence $M_{\mathrm{C}}$. In our case, the interstation distance is around $50 \mathrm{~km}$ suggesting an $M_{\mathrm{C}}$ around 2.3, close to our computed value of 2.5 . Thus, the $M_{\mathrm{C}}$ value of our local catalogue is mainly influenced by the geometry of the network and seems uncorrelated with the sensitivity of the automatic procedure.

\subsection{Comparison of depth estimations}

The largest aftershocks comprised in our new seismic catalogue were previously studied using different location methodologies, giving us the opportunity to quantify hypocentres differences.

First, we compared our depth estimates to those obtained by Letort et al. (2016) using time delays between teleseismic $P$ and depth phases with the cepstral method developed by Letort et al. (2015). Among the 60 events of the aftershock sequence studied by 


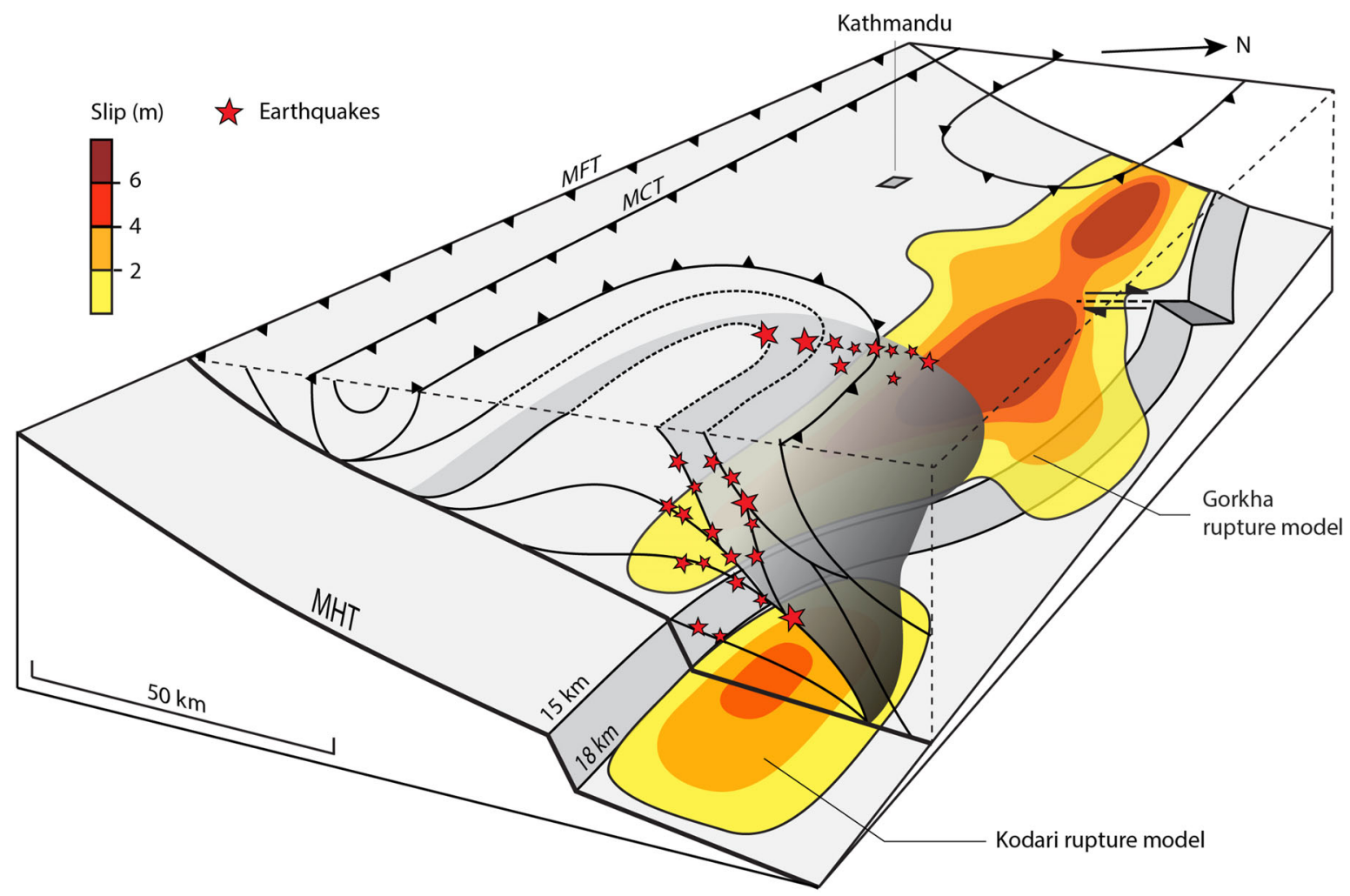

Figure 13. Conceptual model showing the interaction between the geometry of the MHT, the tectonic structures, the ruptures models and the seismicity. Scale exageration is 2:1 in the vertical direction. The MHT presents an overall gently dip towards the east (from 15 to $18 \mathrm{~km}$ depth) and is affected by the presence of a ramp. The ramp exhibits a tear fault that corresponds to a slip low in the Gorkha rupture model. Both Gorkha and Kodari ruptures extents are controlled by the location of the ramp. Stress Coulomb changes associated to the Kodari earthquake generate earthquakes in the hangingwall on out of sequence and roof thrusts in the Himalayan duplex. The Lamosangu antiform (shades of grey) probably dips to the west which is highlighted by an alignment of earthquakes.

Letort et al. (2016) only 25 were sufficiently well located (errors $<7 \mathrm{~km}$ in $X$-, $Y$ - and $Z$-directions) to be properly compared. The difference between the depths is represented on Fig. S3 in the Supporting Information and shows a mean of $2.5 \pm 5.7 \mathrm{~km}$. The depths obtained using the cepstral method and the depths of our catalogue are consistent with each other considering their respective uncertainties. From our locations, we suggest a deeper downdip limit of the seismicity occurring on the MHT, progressively increasing from $15 \mathrm{~km}$ depth to $18 \mathrm{~km}$ depth eastward (Fig. 10).

We also compared locations to those obtained by McNamara et al. (2016) using the hypocentroidal decomposition (HD) method of Jordan \& Sverdrup (1981). The set of 672 events relocated using the HD method is on average 5-10 km deeper than the events of our new and Adhikari et al. (2015) catalogues. This difference is larger than the depth uncertainty associated to the best located events in our catalogue where the average uncertainty on the depths is $6 \mathrm{~km}$. The deeper depths determined by McNamara et al. (2016) fall 5-10 km below the presumed MHT and are interpreted by the authors as belonging to a subducted channel below the MHT. However, according to the local depths we determined, and given their uncertainties, most of the seismicity (especially in the eastern and central region) falls onto, or above, the MHT interface, whose depth is constrained by rupture models and receiver function analysis (Schulte-Pelkum et al. 2005; Nabelek et al. 2009; Duputel et al. 2016). While our catalogue indicates that events tend to deepen eastward, they still remain close to the presumed MHT. Such deep events in McNamara et al. (2016) catalogue might be associated to the velocity model used for inversion. Although their $V_{\mathrm{P}}$ model is close to the one used in our study $\left(5.7 \mathrm{~km} \mathrm{~s}^{-1}\right.$ to be compared to $5.6 \mathrm{~km} \mathrm{~s}^{-1}$ for the first $23 \mathrm{~km}$, derived from Pandey et al. 1995), their $V_{\mathrm{S}}$ model is higher (3.6 km s$~^{-1}$ to be compared to $3.2 \mathrm{~km} \mathrm{~s}^{-1}$ for the first $23 \mathrm{~km}$ ). This leads to a $V_{\mathrm{P}} / V_{\mathrm{S}}$ ratio close to 1.6 resulting in deeper locations.

\subsection{Spatial distribution of the aftershocks versus tectonic structure}

Most aftershocks are distributed at the close periphery of the rupture in regions that sustain a Coulomb stress increase (e.g. Lin \& Stein 2004). However, a closer inspection reveals significant lateral heterogeneities in terms of aftershock distribution with a complexity that appears to be difficult to reconcile with the sole stress concentrations derived from the current smooth slip models and suggesting more discontinuities along the fault surface.

As a matter of example, the aftershock sequence is characterized by a lower seismicity rate along the MHT and in its hangingwall north of Kathmandu (referred as Z1 on Figs 10 and 11) than in the surroundings. This gap is about $10 \mathrm{~km}$ wide, and falls nearby the western border of the Kathmandu Klippe materialized by the MCT trace on Figs 10 and 11. We observe that the location of the seismic gap correlates well with a patch of low slip in the rupture model of the Gorkha earthquake.

Hoste-Colomer et al. (2016) studied the interseismic activity in this region prior to the Gorkha earthquake and relocated a seismic swarm in this area in the vicinity of the epicentre of the main shock and aftershocks of the 1997 January 31 Sarshin earthquake (M 5.8, grey circle on Fig. 11). Interpretation of this swarm led the authors 
to suggest the presence of two 'en-echelon' stepping strands of mid-crustal ramps of the MHT separated by a right-lateral tear fault (Fig. 11).

The seismic gap observed in our data set tends to confirm the hypothesis of an along-strike tectonic segmentation of the Gorkha rupture.

The eastern end of the seismic swarm is confined to a narrow square-shape region $\left(30 \times 30 \mathrm{~km}^{2}\right)$ centred on the fault segment ruptured by the $\mathrm{E} 3$ «Kodari» earthquake.

It falls on the northern limb of the main Lesser Himalayan antiform (Figs 11 and 13). The cross-sections through the seismicity there reveal that the events occur between $18 \mathrm{~km}$ and the surface, and are equally generated in the vicinity of the MHT shear zone and in its hangingwall. The deeper events, including the Kodari earthquake, occurring on the MHT at about $18 \mathrm{~km}$ depth suggest that the critical temperature of $350{ }^{\circ} \mathrm{C}$ above which we observe conditionally stable or stable conditions for quartzo-feldspathic rocks (Blanpied et al. 1995; Marone 1998) is probably not reached (Herman et al. 2010; Ader et al. 2012).

The northern and eastern ends of the E3 aftershocks fall at the foot of an embayment within the high topography, materialized by the trace of the MCT (Fig. 11). The southern and eastern ends of the seismic cluster approximately fall below regional and local anticlinal axes: the main axis of the Okaldhunga window anticlinorium to the south and the local N-S oriented Tamba Kosi Antiform to the east (TKA, Fig. 11; e.g. Schelling 1992; Goscombe \& Hand 2000; Robinson \& Martin 2014).

This suggests a possible control of the E3 rupture and its aftershocks by the local geological structures. Indeed, the shape of the anticlinorium and the geometry of the lesser Himalayas suggest that the mid-crustal ramp should be on average somewhere between the hinge of the anticlinorium and the foot of the high topography. If true, the fault segment ruptured by the E3 earthquake could correspond to a segment of the lower decollement of the MHT, a segment abutting at the bottom of the ramp (Fig. 13).

Furthermore, the antiformal stack of the lesser Himalayan duplex could also be partly responsible for the generation of the seismicity, through out-of-sequence slip on roof thrusts or internal deformation partly accommodated by bedding-slip (Fig. 13).

The seismic productivity, normalized by the surface, appears higher in the trace of the Kodari earthquake $(a$-value $=2.0)$ than within the trace of the Gorkha earthquake $(a$-value $=1.2)$ as revealed by the Gutenberg-Richter diagrams (Fig. S2, Supporting Information, see caption for events selection criteria). This observation is consistent with the presence of a lateral structural heterogeneity between the main Gorkha earthquake trace and the Kodari rupture. Indeed, (1) a seismic rupture abutting at the bottom of a ramp should abruptly taper. The large slip gradient at the rupture end will generate high Coulomb stress variations responsible for enhanced seismicity. (2) The northernmost part of the lesser Himalayan antiform dips at about $40^{\circ}$ to the northeast (e.g. Larson 2012). The multiple north-dipping high angles discontinuities in the lesser Himalayas units, including the roof thrusts of the antiformal stack might focus the seismicity (southernmost discontinuity is referred as SL on profile 4; Fig. 8) and limits its propagation toward south. We propose that the eastern border of seismicity reflects the presence of the W-E oriented Lamosangu antiform that overlaps the TKA to the west. Regarding the apparent unit thickness, this antiform might present a slight dip towards the west (Fig. 13). This dipping could be revealed by the alignment of seismicity, observed on the W-E cross-section (profile 4; Fig. 10), whose dip is estimated to be $\sim 18^{\circ}$.
The shape of the northern cluster is in good agreement with the strike of the $M_{\mathrm{w}} 5.3$ Nyalam normal fault earthquake that occurred on 2015 April 25. This earthquake focal mechanism (Fig. 8) is similar with others located along the $\mathrm{N}-\mathrm{S}$ trending southern Tibetan grabens which accommodate W-E extension within the Tibet Plateau (e.g. Armijo et al. 1986). Li et al. (2016) modeled the Coulomb stresses generated by the E1 earthquake on both nodal planes similar to the Nyalam earthquake. Considering the small static stress Coulomb changes $(\sim 10 \mathrm{kPa})$ and the time delay between E1 and the Nyalam earthquake ( $>10 \mathrm{hr}$ ), they suggest possible secondary processes, such as afterslip, viscous relaxation, or viscoelastic stress transfer, that could lead to the occurrence of this event. Cross-correlation onset arrivals and double difference relocation of this cluster would considerably reduce depth uncertainties and thus allow a better interpretation of the locations in relation to the Nyalam earthquake nodal planes.

The southern cluster exhibits four events $M_{\mathrm{L}}>4$ with a recurrence time of approximately $20 \mathrm{~d}$. Both locations and waveforms are different between events indicating they have different focal mechanisms. Performing multiplet analysis would probably help to obtain composite focal mechanisms (Hardebeck \& Shearer 2002) and better understand the tectonics processes associated to this seismic swarm.

The event of $M_{\mathrm{L}}>4$ that occurs right after E3 is followed by a sudden decrease of the recorded seismic rate. We suggest that E3 might trigger this $M_{\mathrm{L}}>4$ event. We note that this event occurred more than $13 \mathrm{hr}$ after the E3 earthquake, thus, despite the large distance separating cluster B and E3 $(\sim 100 \mathrm{~km})$, we suggest that small static Coulomb stress variations triggered the earthquake rather than dynamic stress changes.

\section{CONCLUSIONS}

The new automatic location procedure introduced in this paper, applied to 3 months of data from the NSC, allowed us to locate more than 9188 events following the April 25 Gorkha earthquake $M_{\mathrm{w}} 7.8$.

First, the automatic procedure revealed its capacity to detect a large number of events. Comparing our results to the detection rate of the manual catalogue in the same time period, the automatic approach detected 1.7 times more events ( 7426 compared to 4401 events for the manual catalogue). Second, events located automatically shows relatively small location errors given the network geometry and density. Typically, errors are $<4.5$ and $<9 \mathrm{~km}$ in the east-west and north-south directions and $<10 \mathrm{~km}$ in depth. This is comparable to manual locations proposed by Adhikari et al. (2015). We also emphasize the ability of the automatic procedure to insure consistency and continuity of the catalogue over long time periods, as it does not depend on human analysts' considerations.

The resulting event catalogue allows us to develop a new local magnitude for the Kathmandu region. This analysis was motivated by the great disparities systematically observed in previous studies between local magnitudes estimates $\left(M_{\mathrm{L}}\right)$ and global magnitudes estimates $\left(M_{\mathrm{w}}\right.$ or $\left.m_{\mathrm{b}}\right)$. Calibration of the $M_{\mathrm{L}}$ was performed using 137 events common to both the automatic catalogue and the NEIC catalogue. The magnitude of completeness of the automatic catalogue is $2.5 M_{\mathrm{L}}$ and the $b$-value around 0.92 .

We observe that most of the depths of deeper events - presumably associated with the MHT — match the depth of the MHT shear zone as determined by Duputel et al. (2016). We further show that, in general, the depths of the aftershocks are close to those obtained by Letort et al. (2016) using time delays between teleseismic $P$ and 
depth phases, confirming an average deepening of the events from west to east (from 15 to $18 \mathrm{~km}$ ).

We propose that the spatiotemporal behaviour of the Gorkha aftershock sequence can be decomposed in three different periods. This decomposition reveals that: (1) most of the magnitude $>5$ earthquakes occurred the day of the main shock; (2) the seismicity is characterized by a clear termination of activity to the east and (3) this termination is characterized by subsequent jump-offs towards east, reaching almost $25 \mathrm{~km}$ after the May $12 M_{\mathrm{w}} 7.3$ main aftershock.

In general, the areas of denser seismic activity surround the main shock rupture model, except north of Kathmandu, where an intense activity is observed close to a maximum slip area suggesting the rupture of small asperities in the vicinity of the MHT shear zone.

Density maps reveal the existence of a seismic gap (referred as $\mathrm{Z} 1$ in this paper) that spatially correlates to a slip minimum. This supports the interpretation of a tear fault affecting the MHT (HosteColomer et al. 2016).

Seismicity associated to the May 12 aftershock is confined to a narrow region whose limits could be associated to the existence of anticlinorium in the Okaldhunga window. The $18^{\circ}$ west dipping alignment of seismicity observed could reveal the geometry of the first-order anticlinorium.

\section{ACKNOWLEDGEMENTS}

We thank the Nepalese DMG (Department of Mines and Geology) for sharing the seismic data used in this study. This study was financially supported by the LRC (Laboratoire de Recherche Conventionné) Yves Rocard. We also sincerely thank Pierre Duperray for his contributions to the project.

\section{REFERENCES}

Ader, T. et al., 2012. Convergence rate across the Nepal Himalaya and interseismic coupling on the Main Himalayan Thrust: implications for seismic hazard, J. geophys. Res., 117(4), 1-16.

Adhikari, L. et al., 2015. The aftershock sequence of the 2015 April 25 Gorkha Nepal earthquake, Geophys. J. Int., 203(3), 2119-2124.

Akaike, H., 2011. Akaike's Information Criterion, in International Encyclopedia of Statistical Science, pp. 25-25, Springer, Berlin, Heidelberg.

Allen, R., 1982. Automatic phase pickers: their present use and future prospects, Bull. seism. Soc. Am., 72(6), 225-242.

Avouac, J.-P., Meng, L., Wei, S., Wang, T. \& Ampuero, J.-P., 2015. Lower edge of locked Main Himalayan Thrust unzipped by the 2015 Gorkha earthquake, Nat. Geosci., 8(9), 708-711.

Armijo, R., Tapponnier, P., Mercier, J.L. \& Han, T.-L., 1986. Quaternary extension in southern Tibet: field observations and tectonic implications, J. geophys. Res., 91(B14), 13803, 13 803-13 872.

Baer, M. \& Kradolfer, U., 1987. An automatic phase picker for local and teleseismic events, Bull. seism. Soc. Am., 77(4), 1437-1445.

Bai, L., Liu, H., Ritsema, J., Mori, J., Zhang, T., Ishikawa, Y. \& Li, G., 2016. Faulting structure above the Main Himalayan Thrust as shown by relocated aftershocks of the $2015 \mathrm{Mw} 7.8$ Gorkha, Nepal, earthquake, Geophys. Res. Lett., 43(2), 637-642.

Baillard, C., Crawford, W.C., Ballu, V., Hibert, C. \& Mangeney, A., 2014. An automatic Kurtosis based P- and S-phase picker designed for local seismic networks, Bull. seism. Soc. Am., 104(1), 394-409.

Baillard, C., Crawford, W.C., Ballu, V., Regnier, M., Pelletier, B. \& Garaebiti, E., 2015. Seismicity and shallow slab geometry in the central Vanuatu subduction zone, J. geophys. Res., 120(8), 5606-5623.

Bettinelli, P., Avouac, J.-P., Flouzat, M., Jouanne, F., Bollinger, L., Willis, P. \& Chitrakar, G.R., 2006. Plate motion of India and interseismic strain in the Nepal Himalaya from GPS and DORIS measurements, J. Geod., 80(8-11), 567-589.
Blanpied, M.L., Lockner, D.A. \& Byerlee, J.D. 1995. Frictional slip of granite at hydrothermal conditions, J. geophys. Res., 100(B7), $13045-13064$.

Bollinger, L., Avouac, J.P., Cattin, R. \& Pandey, M.R., 2004. Stress buildup in the Himalaya, J. geophys. Res., 109(11), 1-8.

Bondar, I. \& Storchak, D., 2011. Improved location procedures at the International Seismological Centre, Geophys. J. Int., 186(3), 1220-1244.

Duputel, Z., Vergne, J., Rivera, L., Wittlinger, G., Farra, V. \& Hetenyi, G., 2016. The 2015 Gorkha earthquake: a large event illuminating the Main Himalayan Thrust fault, Geophys. Res. Lett., 43(6), 2517-2525.

Efron, B., 1982. The Jackknife, the Bootstrap and Other Resampling Plans, SIAM.

Elliott, J.R., Jolivet, R., Gonzalez, P.J., Avouac, J.-P., Hollingsworth, J., Searle, M.P. \& Stevens, V.L., 2016. Himalayan megathrust geometry and relation to topography revealed by the Gorkha earthquake, Nat. Geosci., 9(2), 174-180.

Freedman, H., 1966. The little variable factor a statistical discussion of the reading of seismograms, Bull. seism. Soc. Am., 56(2), 593-604.

Galetzka, J. et al., 2015. Slip pulse and resonance of the Kathmandu basin during the 2015 Gorkha earthquake, Nepal, Science, 349(6252), 10911095.

Goscombe, B. \& Hand, M., 2000. Contrasting PT paths in the Eastern Himalaya, Nepal: inverted isograds in a paired metamorphic mountain belt, J. Petrol., 41(12), 1673-1719.

Grandin, R., vallee, M., Satriano, C., Lacassin, R., Klinger, Y., Simoes, M. $\&$ Bollinger, L., 2015. Rupture process of the $\mathrm{Mw}=7.92015$ Gorkha earthquake (Nepal): insights into Himalayan megathrust segmentation, Geophys. Res. Lett., 42(20), 8373-8382.

Hardebeck, J.L. \& Shearer, P.M., 2002. A new method for determining first-motion focal mechanisms, Bull. seism. Soc. Am., 92(6), 2264-2276.

Havskov, J. \& Ottemoller, L., 1999. SeisAn earthquake analysis software, Seismol. Res. Lett., 70(5), 532-534.

Herman, F. et al., 2010. Exhumation, crustal deformation, and thermal structure of the Nepal Himalaya derived from the inversion of thermochronological and thermobarometric data and modeling of the topography, $J$. geophys. Res., 115(B6), B06407, doi:10.1029/2008JB006126.

Hibert, C. et al., 2014. Automated identification, location, and volume estimation of rockfalls at Piton de la Fournaise volcano, J. geophys. Res., 119(5), 1082-1105.

Hoste-Colomer, R., Bollinger, L., Lyon-Caen, H., Burtin, A. \& Adhikari, L., 2016. Lateral structure variations and transient swarm revealed by seismicity along the Main Himalayan Thrust north of Kathmandu, Tectonophysics, in press, doi:10.1016/j.tecto.2016.10.004.

Hubbard, J., Almeida, R., Foster, A., Sapkota, S.N., Burgi, P. \& Tapponnier, P., 2016. Structural segmentation controlled the $2015 \mathrm{Mw} 7.8$ Gorkha earthquake rupture in Nepal, Geology, 44(8), 639-642.

Jordan, T.H. \& Sverdrup, K.A., 1981. Teleseismic location techniques and their application to earthquake clusters in the South-Central Pacific, Bull. seism. Soc. Am., 71(4), 1105-1130.

Kanamori, H., 1983. Magnitude scale and quantification of earthquakes, Tectonophysics, 93(3-4), 185-199.

Küperkoch, L., Meier, T., Lee, J., Friederich W. \& EGELADOS Working Group, 2010. Automated determination of P-phase arrival times at regional and local distances using higher order statistics, Geophys. J. Int., 181, 1159-1170.

Larson, K.P., 2012. The geology of the Tama Kosi and Rolwaling valley region, East-Central Nepal, Geosphere, 8(2), 507-517.

Letort, J., Guilbert, J., Cotton, F., Bondar, I., Cano, Y. \& Vergoz, J., 2015. A new, improved and fully automatic method for teleseismic depth estimation of moderate earthquakes $(4.5<\mathrm{M}<5.5)$ : application to the Guerrero subduction zone (Mexico), Geophys. J. Int., 201(3), 1834-1848.

Letort, J., Bollinger, L., Lyon-Caen, H., Guilhem, A., Cano, Y., Baillard, C. \& Adhikari, L.B., 2016. Teleseismic depth estimation of the 2015 Gorkha Nepal aftershocks, Geophys. J. Int., 207(3), 1584-1595.

Li, L., Yao, D., Meng, X., Peng, Z. \& Wang, B., 2016. Increasing seismicity in Southern Tibet following the $2015 M_{\mathrm{w}} 7.8$ Gorkha, Nepal earthquake, Tectonophysics, in press, doi:10.1016/j.tecto.2016.08.008. 
Lin, J. \& Stein, R.S., 2004. Stress triggering in thrust and subduction earthquakes and stress interaction between the southern San Andreas and nearby thrust and strike-slip faults, J. geophys. Res., 109(B2), 1-19.

Marone, C. 1998. Laboratory-derived friction laws and their application to seismic faulting, Annu. Rev. Earth Planet. Sci., 26(1), 643-696.

McNamara, D. et al., 2016. Source modeling of the $2015 M_{\mathrm{W}} 7.8 \mathrm{Nepal}$ (Gorkha) earthquake sequence: implications for geodynamics and earthquake hazards, Tectonophysics, doi:10.1016/j.tecto.2016.08.004.

Nabelek, J. et al., 2009. Underplating in the Himalaya-Tibet collision zone revealed by the Hi-CLIMB experiment, Science, 325(5946), 1371-1374.

Nippress, S.E.J., Rietbrock, A. \& Heath, A.E., 2010. Optimized automatic pickers: application to the ANCORP data set, Geophys. J. Int., 181(2), 911-925.

Pandey, M.R., Tandukar, R.P., Avouac, J.P., Lavé, J. \& Massot, J.P., 1995. Interseismic strain accumulation on the Himalayan crustal ramp (Nepal), Geophys. Res. Lett., 22(7), 751-754.

Pandey, M.R., Tandukar, R.P., Avouac, J.P., Vergne, J. \& Heritier, T., 1999. Seismotectonics of the Nepal-Himalaya from a local seismic network, $J$. Asian Earth Sci., 17(5-6), 703-712.

Rajaure, S., Koirala, B., Bhatterai, M., Shrestha, P., Maske, S., Tiwari, D.R. \& Gautam, U., 2011. Calibration of local earthquake magnitudes in Nepal, J. Nepal Geol. Soc., 42, 92-97.

Rietbrock, A., Ryder, I., Hayes, G., Haberland, C., Comte, D., Roecker, S. \& Lyon-Caen, H., 2012. Aftershock seismicity of the 2010 Maule $M_{\mathrm{W}}=8.8$, Chile, earthquake: correlation between coseismic slip models and aftershock distribution?, Geophys. Res. Lett., 39(8), doi:10.1029/2012GL051308.

Ristau, J., 2009. Comparison of magnitude estimates for New Zealand earthquakes: moment magnitude, local magnitude, and teleseismic body-wave magnitude, Bull. seism. Soc. Am., 99(3), 1841-1852.

Robinson, D.M. \& Martin, A.J., 2014. Reconstructing the Greater Indian margin: a balanced cross section in central Nepal focusing on the Lesser Himalayan duplex, Tectonics, 33(11), 2143-2168.

Sapkota, S.N., Bollinger, L., Klinger, Y., Tapponnier, P., Gaudemer, Y. \& Tiwari, D., 2013. Primary surface ruptures of the great Himalayan earthquakes in 1934 and 1255, Nat. Geosci., 6(1), 71-76.

Saragiotis, C., Hadjileontiadis, L. \& Panas, S., 2002. PAI-S/K: a robust automatic seismic $\mathrm{P}$ phase arrival identification scheme, IEEE Trans. Geosci. Remote Sens., 40(6), 1395-1404.

Schelling, D., 1992. The tectonostratigraphy and structure of the eastern Nepal Himalaya, Tectonics, 11(5), 925-943.

Schulte-Pelkum, V., Monsalve, G., Sheehan, A., Pandey, M.R., Sapkota, S., Bilham, R. \& Wu, F., 2005. Imaging the Indian subcontinent beneath the Himalaya, Nature, 435(7046), 1222-1225.

Stocklin, J., 1980. Geology of Nepal and its regional frame: thirty-third William Smith Lecture, J. Geol. Soc., 137(1), 1-34.
Weber, B. et al., 2007. SeisComP3 automatic and interactive real-time data processing, Geophys. Res. Abs., 9, 09219.

Wiemer, S. \& Wyss, M., 2000. Minimum magnitude of completeness in earthquake catalogs: examples from Alaska, the Western United States, and Japan, Bull. seism. Soc. Am., 90(4), (August), 859-869.

Zeiler, C. \& Velasco, A.A., 2009. Seismogram picking error from analyst review (SPEAR): single-analyst and institution analysis, Bull. seism. Soc. Am., 99(5), 2759-2770.

\section{SUPPORTING INFORMATION}

Supplementary data are available at GJIRAS online.

Figure S1. Interevent time delays for events of the manual catalogue. Top: time delays for events that were not detected automatically. Bottom: time delays for events that have been also detected automatically. Events not detected by the automatic procedure tends to occur right before or right after other events ( $\sim 2 \mathrm{~min})$ inhibiting the capacity of the procedure to properly associate phases to events. Figure S2. Normalized Gutenberg-Richter diagrams. White circles take into account the whole catalogue on the 3 months period. Blue circles takes into account events associated to the Gorkha sequence (west of the Kodari rupture trace) during a $17 \mathrm{~d}$ period after the main shock. Red circles takes into account events associated to the Kodari sequence (in the vicinity of the Kodari rupture trace) during a $17 \mathrm{~d}$ period after the 2015 May 12 shock. Number of events per bin is normalized by $S$, the surface of the rupture model. $S$ is $7800 \mathrm{~km}^{2}$ for the Gorkha model (blue), $990 \mathrm{~km}^{2}$ for the Kodari model (red). $S$ is taken as the sum of the two rupture surfaces when dealing with the whole catalogue (white). Note the higher $a$-value for catalogue associated to the Kodari trace compared to the one obtained for the Gorkha trace.

Figure S3. Depth differences between Letort et al. (2016) catalogue and ours for 25 commons events. Note the linear bias with depth. This might be due to the smaller resolution of the cepstral method for shallow events.

Table S1. $P$-wave velocity model used for our study (from Pandey et al. 1995). The $V_{\mathrm{S}}$ model derives from the $V_{\mathrm{S}}$ model using a $V_{\mathrm{P}} / V_{\mathrm{S}}$ ratio equal to 1.75 .

Please note: Oxford University Press is not responsible for the content or functionality of any supporting materials supplied by the authors. Any queries (other than missing material) should be directed to the corresponding author for the paper. 